\title{
Buckling Finite Element Formulation for Sandwich Pipes under External Pressure
}

by Rouzbeh Hashemian ${ }^{\left({ }^{a}\right)}$ and Magdi Mohareb ${ }^{\text {(a) * }}$

(a) Department of Civil Engineering, University of Ottawa, Ottawa, ON, K1N 6N5

\begin{abstract}
A finite element buckling eigenvalue solution is developed for the analysis of sandwich pipes subjected to internal and external hydrostatic pressure. The principle of stationary potential energy is used to formulate the conditions of equilibrium and neutral stability using polar coordinates. The formulation accounts for shear deformation effects and is suited for sandwich pipe systems with thick cores. It involves two destabilizing terms: one is due to the external hydrostatic pressure and incorporates the follower effects, and the other, is due to the pre-bucking stresses undergoing nonlinear components of strains. The formulation adopts a work conjugate triplet consisting the Cauchy stress tensor, the Green Lagrange strain tensor, and constant constitutive relations. A finite element solution is developed and implemented under MATLAB and is then applied to predict the buckling capacity of sandwich pipes consisting of two steel pipes with a soft core. A verification study is conducted, and the validity of the formulation is established through comparison with other solutions. A parametric study is then conducted to investigate the effect of hydrostatic internal pressure, core material, core thickness, internal and external pipe thicknesses, on the buckling capacity of sandwich pipes.
\end{abstract}

*Corresponding author. Tel. +1 (613) 5625800 x 6130, fax +1 (613) 5635173

Email Address: mmohareb@uottawa.ca (M. Mohareb)

Keywords:

Sandwich Pipes, Offshore pipelines, External Pressure, Buckling, Eigenvalue, Finite element, polar coordinates

This article is to be cited as: Rouzbeh Hashemian and Magdi Mohareb (2016) Buckling finite element formulation for sandwich pipes under external pressure, International Journal of Pressure Vessels and Piping, 147: 41-54, ISSN 0308-0161.

The copy-edited version of this article is available at https://doi.org/10.1016/j.ijpvp.2016.09.006 


\section{Introduction}

With the continuous search of oil and gas at deep sub-sea depths, offshore pipelines are being built at depths of more than $2000 \mathrm{~m}$. In such situations involving high external pressure, conventional engineering solutions involving thick steel pipes can become uneconomic when compared to sandwich pipe systems. Sandwich pipes consist of an internal steel pipe, a core layer made from a relatively soft material with elastic modulus values typically ranging from 25 to 2500 (Sato et al. 2008), and external high strength steel pipe. Within this context, the present study develops an accurate and efficient finite element solution for the buckling analysis of sandwich pipes under the effect of external pressure and internal pressure and subsequently uses the model to conduct parametric studies.

\section{Literature review}

The primary focus of the present study is developing an eigen-value solution the buckling of sandwich pipe systems. Since sandwich systems involve a thick core, existing buckling eigensolutions for thick pipes are surveyed (Section 2.1) prior to buckling eigen-solutions for sandwich pipe systems (Section 2.2).

\subsection{Thick Pipes under External Pressure}

Earlier buckling studies on thin rings (e.g. Bodner (1958), Koiter (1963), Wah (1967), Hutchinson (1968), Singer and Babcock (1970), and Amazigo and Fraser (1971)) neglected shear deformation effects within the thickness. When the thickness increases, shear deformation will have a considerable effect on the behavior of the ring. Thus, the critical pressure predicted by the thin ring theory is expected to deviate significantly from that based on thick ring formulation. Using the second Piola-Kirchhoff stress tensor, Kardomateas (1993) developed an elasticity solution for the buckling of orthotropic cylindrical thick shells. Fu and Waas (1995) developed a buckling solution and an initial post-buckling solution. The first analysis was based on shear deformable model by assuming the displacement to vary linearly across the thickness. The second analysis was a 2D formulation based on a variational approach. Papadakis (2008) developed the neutral stability conditions for thick pipes by considering the effect of transverse shear. His solution considered the destabilizing effect caused by stresses undergoing non-linear strains. Most recently, 
Ji and Waas (2013) formulated three 2D elasticity solutions. The first solution considered a work conjugate stress-strain relation. The second solution demonstrated the effect of the follower force throughout buckling where the tractions were not transformed to the deformed configuration, and the third solution was aimed at demonstrating the limitations of commercial FEA software such as ABAQUS. In their treatment, the authors formulated a solution based upon the Jaumann rate of the Kirchhoff stress tensor, the Green Lagrange Strain tensor, and a constant constitutive tensor.

\subsection{Sandwich Pipes under External Pressure}

Brush and Almroth (1975) formulated an approximate buckling solution for sandwich pipes based on a ring on elastic foundation analogy. Their solution neglects the contribution of the inside pipe and the thickness of the core. Kardomateas and Simitses (2004) developed a 3D buckling solution for sandwich cylindrical shells under external pressure by incorporating shear deformation effects. They reported that the omission of transverse shear effects leads to highly non-conservative critical pressures. Sato and Patel (2007) investigated the elastic buckling pressure of sandwich pipes involving two thin pipes with thick core layer. In their solution, the authors adopted the internal strain energy expression in Brush and Almroth (1975) for the outer and inner pipes. As a simplification, the solution neglected the non-linear components of the strain-displacement relations within the core. This approximation lent itself to the adoption of the classical Airy stress function solution to characterize the behaviour of the core. A key difference between the present study and that by Sato and Patel (2007) is the retention of the non-linear strain displacement components for the core. Also, based on a stress function approach, Arjomandi and Taheri (2010) developed an analytical solution for the buckling pressure of sandwich pipes. In a manner similar to the work of Sato and Patel (2007), the solution omitted the non-linear strain components within the core. The authors developed solutions for four cases involving various bonding sceanrios: a) fully bonded to both inner and outer pipes, b) un-bonded to the outer pipe, but fully bonded to the inner pipe, c) un-bonded to the inner pipe, but fully bonded to the outer pipe, and d) unbonded to both inner and outer pipe. Table 1 provides a comparative summary for the various features of the above studies along with those of the present study. Also shown are the features and limitations of ABAQUS FEA solution based on an eigenvalue analysis model. As shown in the table, the present study is aimed at capturing shear deformation effects in the steel pipe and the core, the destabilizing terms due to the follower effects, and pre-buckling stresses undergoing non-linear strains, and 
contribution to the internal pipe. A distinctive feature not captured in previous model is the adoption of work conjugate stress-strain-constitutive model triplets.

Table 1 Comparative summary for the various features of the various studies along with those of the present study

\begin{tabular}{|c|c|c|c|c|c|c|c|}
\hline \multirow[b]{2}{*}{ Study } & \multicolumn{2}{|c|}{$\begin{array}{c}\text { Shear } \\
\text { Deformation }\end{array}$} & \multicolumn{2}{|c|}{$\begin{array}{c}\text { Destabilizing terms } \\
\text { due to }\end{array}$} & \multirow[b]{2}{*}{$\begin{array}{c}\text { Contribution } \\
\text { of Internal } \\
\text { Pipe } \\
\text { Captured }\end{array}$} & \multirow[b]{2}{*}{$\begin{array}{c}\text { Work } \\
\text { Conjugate } \\
\text { Triplets }\end{array}$} & \multirow{2}{*}{$\begin{array}{c}\text { Multiple } \\
\text { Condition } \\
\text { s at } \\
\text { Pipe-core } \\
\text { Interfaces }\end{array}$} \\
\hline & $\begin{array}{l}\text { Steel } \\
\text { Pipe }\end{array}$ & Core & $\begin{array}{c}\text { Follower } \\
\text { Force } \\
\text { Effect }\end{array}$ & $\begin{array}{c}\text { Pre-buckling } \\
\text { Stresses } \\
\text { Undergoing } \\
\text { Non-linear } \\
\text { Strains } \\
\end{array}$ & & & \\
\hline $\begin{array}{l}\text { Brush and } \\
\text { Almroth } \\
(1975)\end{array}$ & - & - & $\checkmark$ & - & - & - & - \\
\hline $\begin{array}{c}\text { Sato and } \\
\text { Patel } \\
(2007)\end{array}$ & - & $\checkmark$ & $\checkmark$ & - & $\checkmark$ & - & - \\
\hline $\begin{array}{l}\text { Arjomandi } \\
\text { and Taheri } \\
(2011)\end{array}$ & - & $\checkmark$ & $\checkmark$ & - & $\checkmark$ & - & $\checkmark$ \\
\hline $\begin{array}{l}\text { ABAQUS } \\
\text { (CPE8R) }\end{array}$ & $\checkmark$ & $\checkmark$ & - & $\checkmark$ & $\checkmark$ & - & - \\
\hline $\begin{array}{l}\text { Present } \\
\text { Study }\end{array}$ & $\checkmark$ & $\checkmark$ & $\checkmark$ & $\checkmark$ & $\checkmark$ & $\checkmark$ & - \\
\hline
\end{tabular}

\section{Formulation}

\subsection{Statement of the Problem}

Consider a long sandwich pipe system involving $l$ layers with different materials (Figure 1). Each layer has an internal radius $r_{j-1}$ and an external radius $r_{j}$, and thickness $d_{j}=r_{j}-r_{j-1}$ (Figure 1 (a)). The pipe system is assumed to be subjected to a constant internal hydrostatic pressure Pint acting on the inside radius $r_{0}$ and a gradually increasing external hydrostatic pressure $P_{\text {ext }}$ acting on the outside radius $r_{l}$. Sign conventions of both pressures are shown in Figure 1 (b). It is required to determine the external pressure Pext at which the sandwich pipe system will buckle. 


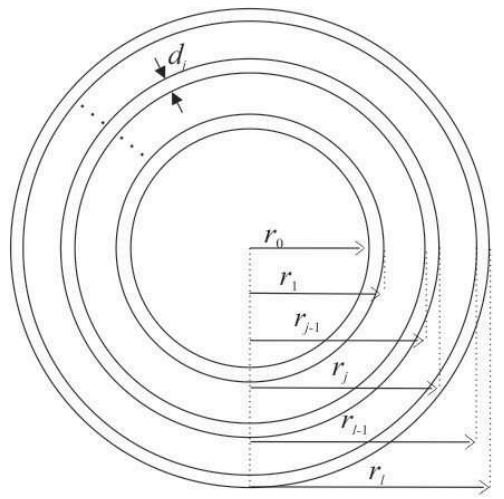

(a)

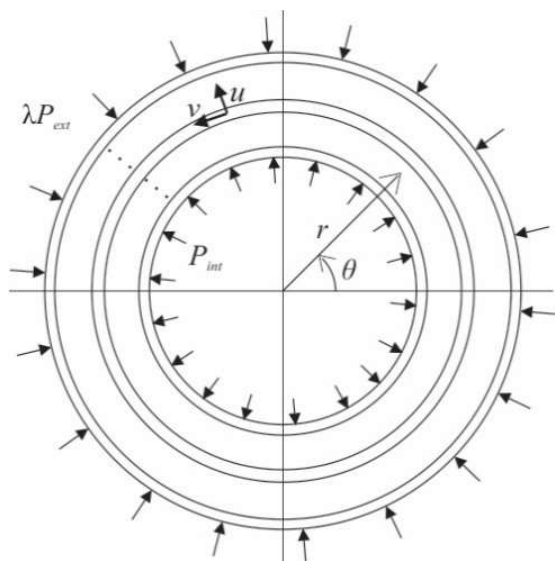

(b)

Figure 1. (a) dimensions of sandwich pipe, (b) Internal and external pressure acting in a multilayer sandwich pipe system

\subsection{Assumptions}

The formulation is based on the following assumptions:

1. Since the pipe length is several orders of magnitude larger than the pipe radii, the problem is idealized as a plane strain problem,

2. For each layer, material is assumed linearly elastic and isotropic,

3. The sandwich pipe system is subjected only to hydrostatic pressures (both internal and external). Both pressures are assumed to remain normal to the deformed pipe surface, i.e., the follower effect is to be captured within the model, and

4. Full bonding is assumed between various layers of the sandwich pipe system

\section{Kinematics and Notation}

It is expedient to adopt the polar coordinates system $(r, \theta)$ (Figure 1b). Displacement $u$ is taken along the radial direction $r$ and displacement $v$ along the tangential direction $\theta$. Configuration a in Figure 2 is that of the system in the initial configuration prior to applying any loading. When the internal pressure $P_{i n t}$ is applied to the inside surface of the sandwich system, the system is assumed to undergo a radial pre-buckling displacements $u_{p I}$ (Configuration 2). An external pressure $P_{e x t}$ is then introduced to the outer surface of the pipe, causing it to deform from configuration $b$ to Configuration $\mathrm{c}$. The deformation associated with the additional contribution of the external pressure is characterized by the pre-buckling displacement $-u_{p E}$ and is to be superimposed on the 
pre-buckling displacement field $u_{p I}$, i.e., the displacement field at Configuration (c) is $u_{p I}-u_{p E}$. The internal pressure $P_{i n t}$ is then assumed to remain constant while the external pressure is assumed to increase until the pipe attains the state of onset of buckling at an external pressure $\lambda P_{e x t}($ Configuration $\mathrm{d})$. The corresponding displacement associated with configuration (d) becomes $u_{p I}-\lambda u_{p E}$, in which $\lambda$ is the sought eigenvalue. It is noted here that $u_{p E}$ is positive in the outward direction, consistently with the sign convention of the radial coordinate $r$. Thus, under the external pressure as defined in Figure 1, its magnitude will be negative. As the pipe buckles (i.e., going from Configuration $\mathrm{d}$ to Configuration e), the applied pressures $P_{i n t}$ and $\lambda P_{\text {ext }}$ are assumed to remain constant. Throughout this stage, the pipe undergoes buckling manifested through additional radial displacements $u_{b}$ and tangential displacements $v_{b}$. At Configuration e the total displacement fields are obtained by summing the displacement field at the onset of buckling to those during buckling, yielding

$$
\begin{aligned}
& u^{*}=u_{p I}-\lambda u_{p E}+u_{b} \\
& v^{*}=0+v_{b}
\end{aligned}
$$

In the above, as a convention, all displacement fields induced in the pre-buckling stage are denoted with a subscript $p$ while all those fields occurring during the buckling stage are denoted with subscript $b$. A superscript $*$ denotes displacements in the final buckling state (i.e., in going from configuration a to configuration e). The above notation convention is also extended to other fields such as strains and stresses.

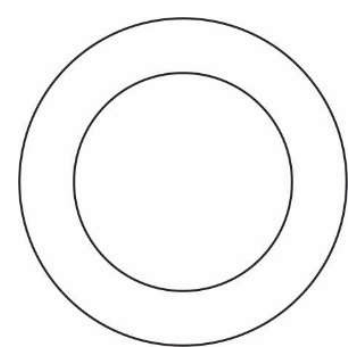

(a)

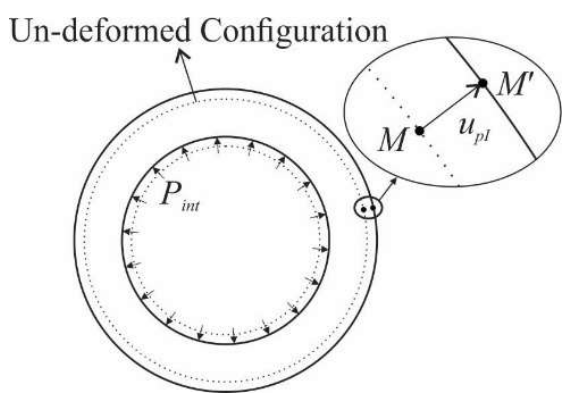

(b) 


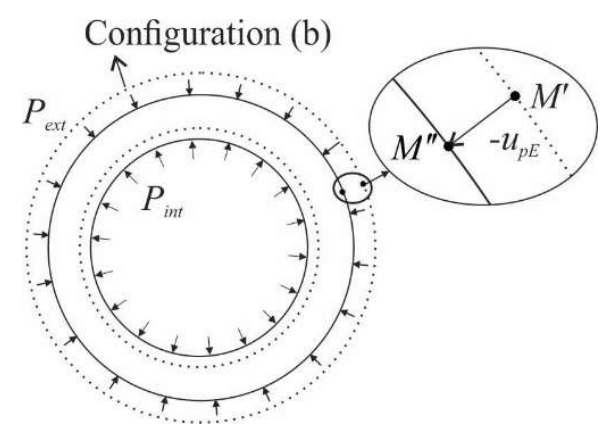

(c)

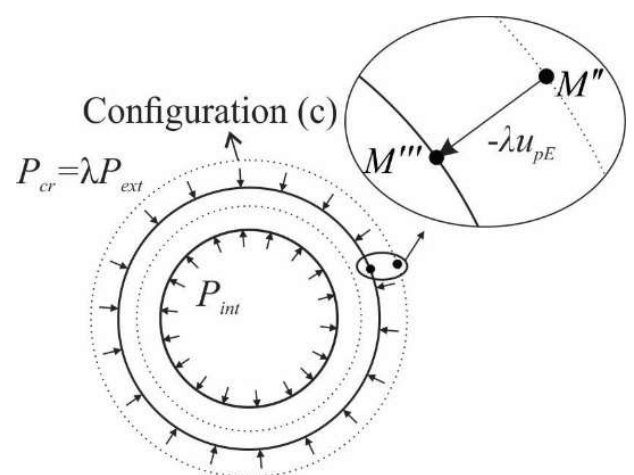

(d)

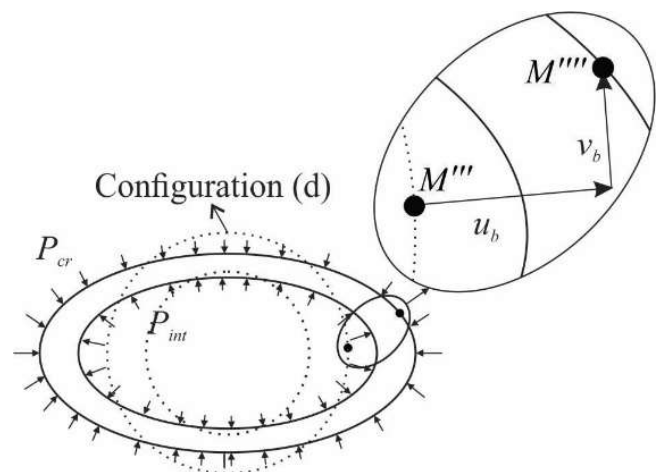

(e)

Figure 2 Kinematics of sandwich pipe (a) un-deformed configuration, (b) pre-buckling configuration under internal pressure, (c) pre-buckling configuration under internal and reference external pressure, (d) onset of buckling, and (e) buckled configuration

\subsection{Strain-Displacement Relationship}

The finite strain displacement relations in 2D polar coordinates (e.g., Kardomateas (1993) are

$$
\begin{aligned}
& \varepsilon_{r}=u^{\prime}+\frac{1}{2}\left(u^{\prime 2}+v^{\prime 2}\right) \\
& \varepsilon_{\theta}=\frac{1}{r}(u+\dot{v})+\frac{1}{2 r^{2}}\left[\dot{u}^{2}+v^{2}-2 \dot{u} v+u^{2}+\dot{v}^{2}+2 u \dot{v}\right] \\
& \gamma_{r \theta}=\frac{1}{r}(\dot{u}-v)+v^{\prime}+\frac{1}{r}\left(\dot{u} u^{\prime}-u^{\prime} v+u v^{\prime}+v^{\prime} \dot{v}\right)
\end{aligned}
$$

where all primes denote the differentiation of the argument function with respect to the radial coordinate $r$, and all dots denote the differentiation of with respect to $\theta$.

\subsection{Strain Decomposition}

From Eqs. (1), by substituting into Eq. (2), one obtains the total strains in terms of the pre-buckling and buckling displacements. Also, the strains can be divided into linear and nonlinear strains. As a convention, all the linear strain components are indicated with subscript $L$ while the non-linear 
strains are denoted with subscript $N L$. Using this notation, each of the total strains (i.e., in going from configuration a to configuration d) consists of four components

$$
\varepsilon_{i}^{*}=\varepsilon_{i, L, p}+\varepsilon_{i, N L, p}+\varepsilon_{i, L, b}+\varepsilon_{i, N L, b} \quad i=r, \theta, r \theta
$$

where $\varepsilon_{r}{ }^{*}$ is the total radial strain, $\varepsilon_{\theta}{ }^{*}$ is the total tangential strain and $\gamma_{r \theta}{ }^{*}$ is the total shear strain. Expressions for the components of Eq. (3) are given in Table 2.

Table 2 Expressions for Linear and non-linear strains

\begin{tabular}{|c|c|c|c|c|}
\hline & \multicolumn{2}{|c|}{$\begin{array}{c}\text { Total Strains in Configuration } \\
(\mathrm{d})\end{array}$} & $\begin{array}{r}\text { Additional strains in going from Configuration } \\
(\mathrm{d}) \text { to Configuration (e) }\end{array}$ \\
\hline & Linear & Non-linear & Linear & Non-linear \\
\hline$\varepsilon_{r}^{*}$ & $u_{p I}^{\prime}+\lambda u_{p E}^{\prime}$ & $1 / 2\left(u_{p I}^{\prime}+\lambda u_{p E}^{\prime}\right)^{2}$ & $u_{b}^{\prime}$ & $1 / 2\left[u_{b}^{\prime 2}+v_{b}^{\prime 2}+2\left(u_{p I}^{\prime}+\lambda u_{p E}^{\prime}\right) u_{b}^{\prime}\right]$ \\
\hline$\varepsilon_{\theta}^{*}$ & $\frac{1}{r}\left(u_{p I}^{\prime}+\lambda u_{p E}^{\prime}\right)$ & $\frac{1}{2 r^{2}}\left(u_{p I}+\lambda u_{p E}\right)^{2}$ & $\frac{1}{r}\left(u_{b}+\dot{v}_{b}\right)$ & $\begin{array}{r}\left(1 / 2 r^{2}\right)\left[\dot{u}_{b}^{2}+v_{b}^{2}-2 \dot{u}_{b} v_{b}+u_{b}^{2}\right. \\
+2\left(u_{p i}+\lambda u_{p e}\right) u_{b}+\dot{v}_{b}^{2} \\
+2\left(u_{p i}+\lambda u_{p e}+u_{b}\right) \dot{v}_{b}\end{array}$ \\
\hline$\gamma_{r \theta}^{*}$ & - & - & $\frac{1}{r}\left(\dot{u}_{b}-v_{b}\right)+v_{b}^{\prime}$ & $\begin{array}{c}-\left(u_{p I}^{\prime}+\lambda u_{p E}^{\prime}+u_{b}^{\prime}\right) v_{b} \\
\left.+\left(u_{p I}+\lambda u_{p E}+u_{b}\right) v_{b}^{\prime}+v_{b}^{\prime} \dot{v}_{b}\right]\end{array}$ \\
\hline
\end{tabular}

\subsection{Total Potential Energy}

For a sandwich pipe system with $j=1,2, \ldots l$ layers, the total potential energy equation is the summation of internal strain energy of each layer $U_{j}$ and load potential gained by the internal pressure $W_{1}$ and that by the external pressure $W_{2}$ i.e.,

$$
\Pi=\sum_{j=1}^{l} U_{j}+W_{1}+W_{2}
$$

where the internal strain energy for a single layer pipe $U_{j}$ is given by Brush and Almroth (1975)

$$
U_{j}=\frac{L_{j}}{2 v} \int_{r_{0}}^{r_{j}} \int_{0}^{2 \pi}\left[\left(1-v_{j}\right)\left(\varepsilon_{r}^{* 2}+\varepsilon_{\theta}^{* 2}\right)+2 v \varepsilon_{r}^{*} \varepsilon_{\theta}^{*}+\frac{1-2 v}{2} \gamma_{r \theta}^{* 2}\right] r d \theta d r
$$


and the generalized destabilizing term due to the internal and external pressure (e.g., Pearson (1956) is

$$
\begin{aligned}
& W_{1}=-P_{\text {int }} \int_{0}^{2 \pi}\left[u^{*} r+\frac{1}{2}\left(v^{* 2}+u^{* 2}-v^{*} \dot{u}^{*}+\dot{v}^{*} u^{*}\right)\right]_{r_{0}} d \theta \\
& W_{2}=\lambda P_{\text {ext }} \int_{0}^{2 \pi}\left[u^{*} r+\frac{1}{2}\left(v^{* 2}+u^{* 2}-v^{*} \dot{u}^{*}+\dot{v}^{*} u^{*}\right)\right]_{r_{l}} d \theta
\end{aligned}
$$

where in Eqs. (5) and (6) $L_{j}=E_{j} v_{j} /\left(1-v_{j}\right)\left(1+2 v_{j}\right)$ is the Lame's constant and $v_{j}$ is the Poisson's ratio for Layer $j$.

\subsection{Pre-Buckling Analysis}

The deformational response corresponding to configurations b-d in Figure 2 is to be determined from the equilibrium condition in pre-buckling state. Throughout pre-buckling, the nonlinear strain components are assumed negligible. The total potential energy $\Pi_{p}$ is obtained by omitting the buckling displacements in Eqs. (5) and (6), and evoking the stationarity condition $\bar{\Pi}_{p}=0$, yielding

$$
\begin{aligned}
\bar{\Pi}_{p}=\sum_{j=1}^{l} & \left\{\int_{r_{j-1}}^{r_{j}} \int_{0}^{2 \pi} \frac{L_{j}}{2 v_{j}}\left[\left(1-v_{j}\right)\left(2 r u_{p, j}^{\prime} \bar{u}_{p, j}^{\prime}+2 \frac{1}{r} u_{p, j} \bar{u}_{p, j}\right)+2 v_{j} u_{p, j} \bar{u}_{p, j}+2 v_{j} u_{p, j}^{\prime} \bar{u}_{p, j}\right] d \theta d r\right\} \\
& +\lambda P_{\text {ext }} \int_{0}^{2 \pi}\left(r \bar{u}_{p}\right)_{r_{l}} d \theta-P_{\text {int }} \int_{0}^{2 \pi}\left(r \bar{u}_{p}^{1}\right)_{r_{0}} d \theta=0
\end{aligned}
$$

where $\overline{()}$ denotes the first variation of the argument function and $u_{p, j}=u_{p, j}(\lambda)$ denotes the prebuckling displacement of Layer $j$ due to the combined effect of external and internal pressures. The dependence of $u_{p, j}(\lambda)$ on $\lambda$ makes the expression valid for Configurations b-d, i.e., $u_{p, j}(\lambda=0), \quad u_{p, j}(\lambda=1)$, and $u_{p, j}(\lambda)$ denote the pre-buckling radial displacements for Configurations b-d, respectively. The pre-buckling displacement due to the internal pressure alone is $u_{p I, j}=u_{p, j}(\lambda=0)$ and the pre-buckling displacement due to the external pressure alone is $u_{p E, j}=u_{p, j}(\lambda=1)-u_{p, j}(\lambda=0)$. Integration by parts of Eq. (7) leads to $l$ equilibrium equations associated with the $l$ layers of the systems of the form $(1 / r) u_{p, j}(\lambda)-u_{p, j}^{\prime}(\lambda)-r u_{p, j}^{\prime \prime}(\lambda)=0$ where $r_{j-1} \leq r \leq r_{j}$ and $j=1,2, \cdots l$. The closed form solution of the field equations is given by 
$u_{p, j}(\lambda)=\bar{F}_{1, j}(\lambda) r+\bar{F}_{2, j}(\lambda) r^{-1} \quad r_{j-1} \leq r \leq r_{j}$

where constants of integration $\bar{F}_{1, j}(\lambda), \bar{F}_{2, j}(\lambda)$ are obtained from the boundary conditions and the interlayer continuity equations. The boundary conditions at the internal and external surfaces arise from the boundary terms resulting from integration by parts and take the form

$$
\begin{array}{ll}
r_{0} P_{i n t}+\left[\left(1-v_{j}\right) / v_{j}\right] L_{j} r_{0} u_{p, j}^{\prime}+L_{j} u_{p, j}=0, & j=1 \\
r_{l} \lambda P_{\text {ext }}+\left[\left(1-v_{j}\right) / v_{j}\right] L_{j} r_{l} u_{p, j}^{\prime}+L_{j} u_{p, j}=0, & j=l
\end{array}
$$

In addition, by grouping the boundary terms the interlayers, one recovers $l-1$ continuity equations

$$
\left\{\left[\left(1-v_{j}\right) / v_{j}\right] L_{j} r_{j} u_{p, j}^{\prime}\left(r_{j}\right)+L_{j} u_{p, j}\left(r_{j}\right)\right\}-\left\{\left[\left(1-v_{j+1}\right) / v_{j+1}\right] L_{j+1} r_{j} u_{p, j+1}^{\prime}\left(r_{j}\right)+L_{j+1} u_{p, j+1}\left(r_{j}\right)\right\}=0
$$

\subsection{Buckling Analysis}

In order to investigate the neutral stability condition of the system, the variation of the second variation of the total potential energy has to vanish. The second variation of the total potential energy is written in terms of the nodal displacement. Then, the conditions of neutral stability are recovered by setting its variation to zero.

\subsubsection{Second Variation of Total Potential Energy in Terms of Displacements}

The second variation of total potential energy can be shown to take the form (Hashemian 2014) 


$$
\begin{aligned}
\frac{1}{2} \overline{\bar{\Pi}}=\delta \sum_{j=1}^{l} & \left\{\int_{r_{j-1}}^{r_{j}} \int_{0}^{2 \pi} \frac{L_{j}\left(1-v_{j}\right)}{2 v_{j}}\left[r\left(\bar{u}_{b}^{\prime}\right)^{2}+\frac{1}{r}\left(\bar{u}_{b}+\overline{\dot{v}}_{b}\right)^{2}\right]+L_{j} \bar{u}_{b}{ }_{b}\left(\bar{u}_{b}+\overline{\dot{v}}_{b}\right)\right. \\
& +\frac{L_{j}\left(1-v_{j}\right)}{2 v_{j}}\left[\left(u_{p, I}+\lambda u_{p, E}\right) \frac{1}{2}\left(2{\overline{u^{\prime}}}_{b}^{2}+2{\overline{v^{\prime}}}_{b}^{2}\right)+\frac{1}{2} r\left({u_{p, I}^{\prime}}^{2}+\lambda u_{p, E}^{\prime}\right)\left(2{\overline{u^{\prime}}}_{b}^{2}+2{\overline{v^{\prime}}}_{b}^{2}\right)\right] \\
& +\frac{L_{j}\left(1-2 v_{j}\right)}{4 v_{j}} r\left(\frac{1}{r} \overline{\dot{u}}_{b}-\frac{1}{r} \bar{v}_{b}+{\overline{v^{\prime}}}_{b}\right)^{2}+\frac{1}{2} L_{j}\left[\frac{1}{2}\left(u_{p, I}+\lambda u_{p, E}\right)\left(2{\overline{u^{\prime}}}_{b}^{2}+2{\overline{v^{\prime}}}_{b}^{2}\right)\right. \\
& \left.\left.+\frac{1}{2 r}\left(u_{p, I}^{\prime}+\lambda u_{p, E}^{\prime}\right)\left(2 \overline{\dot{u}}_{b}^{2}+2 \bar{v}_{b}^{2}-4 \overline{\dot{u}}_{b} \bar{v}_{b}+2 \bar{u}_{b}^{2}+2 \overline{\dot{v}}_{b}^{2}+4 \bar{u}_{b} \overline{\dot{v}}_{b}\right)\right]\right\} d \theta d r \\
& -\frac{1}{2} P_{i n t} \int_{0}^{2 \pi}\left[\left(\bar{v}_{b}\right)^{2}+\left(\bar{u}_{b}\right)^{2}-\bar{v}_{b} \overline{\dot{u}}_{b}+\overline{\dot{v}}_{b} \bar{u}_{b}\right] d \theta \\
+ & \frac{1}{2} \lambda P_{e x t} \int_{0}^{2 \pi}\left[\left(\bar{v}_{b}\right)^{2}+\left(\bar{u}_{b}\right)^{2}-\bar{v}_{b} \overline{\dot{u}}_{b}+\overline{\dot{v}}_{b} \bar{u}_{b}\right] d \theta
\end{aligned}
$$

where $\overline{\overline{()}}$ indicates the second variation of the total potential functional. A finite difference solution based on the above functional has been developed in Hashemian and Mohareb (2015, 2016 ). The present study complements the previous work by formulating a finite element solution. The displacement variations $\bar{u}_{b}(r, \theta), \bar{v}_{b}(r, \theta)$ in Eq. (11) can be expressed as the summation of an infinite number of functions $\bar{u}_{b n}(r), \bar{v}_{b n}(r)$ multiplied by the harmonic functions $\cos n \theta$ and $\sin n \theta$, i.e.,

$$
\bar{u}_{b}(r, \theta)=\sum_{n=2}^{\infty} \bar{u}_{b n}(r) \cos n \theta, \quad \bar{v}_{b}(r, \theta)=\sum_{n=2}^{\infty} \bar{v}_{b n}(r) \sin n \theta
$$

\subsubsection{Displacement Fields in Terms of Nodal Displacements}

The buckling displacement fields $\bar{u}_{b n}(r)$ and $\bar{v}_{b n}(r)$ in Eq. (12) are written in terms of nodal displacements of layer $j$, i.e., $\left\{U_{n, j}\right\}$ and $\left\{V_{n, j}\right\}$ as

$$
\begin{gathered}
\left\{\bar{u}_{b n}(r) \quad \bar{v}_{b n}(r)\right\}=\left\langle N_{j}\right\rangle^{T}\left\{\begin{array}{ll}
U_{n, j} & \left.V_{n, j}\right\}
\end{array}\right\}=\left\langle N_{j, 1}(r) \quad N_{j, 2}(r)\right\rangle\left\{\begin{array}{ll}
u_{n}\left(r_{j, 0}\right) & v_{n}\left(r_{j, 0}\right) \\
u_{n}\left(r_{j, 1}\right) & v_{n}\left(r_{j, 1}\right)
\end{array}\right\} \\
r_{j, 0} \leq r \leq r_{j, 1}, \quad j=1,2,3, \ldots l
\end{gathered}
$$

where $N_{j, 1}$ and $N_{i, 2}$ are the shape functions. A linear interpolation is adopted, i.e., 


$$
N_{j, 1}(r)=\frac{r_{j}-r}{d_{j}}, \quad N_{j, 2}(r)=\frac{r-r_{j-1}}{d_{j}}
$$

From Eqs. (14), by substituting into Eq.(13), one can write the buckling displacements in terms of nodal displacements as

$$
\left[\begin{array}{ll}
\bar{u}_{b}(r, \theta) & \bar{v}_{b}(r, \theta)
\end{array}\right]=\sum_{n=2}^{\infty}\left\langle N_{j}(r)\right\rangle^{T}\left\{\begin{array}{ll}
U_{n, j} \cos n \theta & \left.V_{n, j} \sin n \theta\right\}
\end{array} \quad \begin{array}{l}
r_{j-1} \leq r \leq r_{j} \\
j=1,2,3, \ldots l
\end{array}\right.
$$

\subsubsection{Second Variation of Total Potential Energy in Terms of Nodal Displacements}

From Eq. (15), by substituting into Eq. (11) and using the orthogonality condition, i.e., $\int_{0}^{2 \pi} \cos n \theta \cos m \theta d \theta=\int_{0}^{2 \pi} \sin n \theta \cos m \theta d \theta=0$ where $n \neq m$ and the identities $\int_{0}^{2 \pi} \cos ^{2} n \theta d \theta=$ $\int_{0}^{2 \pi} \sin ^{2} n \theta d \theta=\pi$, one can eliminate the dependence of the displacement functions on $\theta$ in Eq. (11). The second variation of the total potential energy is then expressed in terms of the nodal displacements $\left\{U_{n}\right\}=\left\langle\begin{array}{lllll}U_{n, 1} & \ldots & U_{n, j} & \ldots & U_{n, l}\end{array}\right\rangle^{T}$ and $\left\{V_{n}\right\}=\left\langle\begin{array}{lllll}V_{n, 1} & \ldots & V_{n, j} & \ldots & V_{n, l}\end{array}\right\rangle^{T}$ as

$$
\begin{aligned}
\frac{1}{2} \overline{\bar{\Pi}}=\pi \sum_{n=2}^{\infty}\left\langle\left\{U_{n}\right\}^{T}\left[C_{e, u, n}\right]\left\{U_{n}\right\}+\left\{V_{n}\right\}^{T}\left[C_{e, v, n}\right]\left\{V_{n}\right\}+\left\{U_{n}\right\}^{T}\left[C_{e, u v, n}\right]\left\{V_{n}\right\}\right. \\
+\left\{U_{n}\right\}^{T}\left[C_{g, u, n, I}\right]\left\{U_{n}\right\}+\left\{V_{n}\right\}^{T}\left[C_{g, v, n, I}\right]\left\{V_{n}\right\}+\left\{U_{n}\right\}^{T}\left[C_{g, u v, n, I}\right]\left\{V_{n}\right\} \\
\left.+\lambda\left(\left\{U_{n}\right\}^{T}\left[C_{g, u, n, E}\right]\left\{U_{n}\right\}+\left\{V_{n}\right\}^{T}\left[C_{g, v, n, E}\right]\left\{V_{n}\right\}+\left\{U_{n}\right\}^{T}\left[C_{g, u v, n, E}\right]\left\{V_{n}\right\}\right)\right\rangle
\end{aligned}
$$

where all the coefficient matrices $\left[C_{e, u, n}\right],\left[C_{e, v, n}\right] \ldots$, and $\left[C_{g, u v, n, E}\right]$ are defined in Appendix 1

\subsubsection{Condition of neutral stability}

The condition of neutral stability is obtained by vanishing the variation of the second variation of the total potential energy for an arbitrary set of buckling deformations, i.e., $\delta(1 / 2 \overline{\bar{\Pi}})=\delta[1 / 2(\overline{\bar{U}}+\overline{\bar{W}})]=0$ leading to a series of independent eigenvalue problems for modes $n=2,3 \ldots \infty$, given by 


$$
\begin{aligned}
& \left\{\begin{array}{c:c}
{\left[C_{e, u}\right]+\left[C_{e, u}\right]^{T}+\left[C_{g, u, I}\right]+\left[C_{g, u, I}\right]^{T}} & {[0]} \\
\hdashline[0] & {\left[C_{e, u v}\right]+\left[C_{g, u v, I}\right]}
\end{array}\right]+ \\
& \left.\lambda\left[\begin{array}{c:c}
{\left[C_{g, u, E}\right]+\left[C_{g, u, E}\right]^{T}} & {[0]} \\
\hdashline[0] & {\left[C_{g, u v, E}\right]}
\end{array}\right]\right\}\left\{\left\{\begin{array}{l}
\left\{U_{n}\right\} \\
\left.\hdashline V_{n}\right\}
\end{array}\right\}=0\right. \\
& \left\{\begin{array}{c:c}
{\left[C_{e, u v}\right]^{T}+\left[C_{g, u v, I}\right]^{T}} & {[0]} \\
\hdashline[0] & {\left[C_{e, v}\right]+\left[C_{e, v}\right]^{T}+\left[C_{g, v, I}\right]+\left[C_{g, v, I}\right]^{T}}
\end{array}\right]+ \\
& \left.\lambda\left[\begin{array}{c:c}
{\left[C_{g, v v, E}\right]^{T}} & {[0]} \\
\hdashline[0] & {\left[C_{g, v, E}\right]+\left[C_{g, v, E}\right]^{T}}
\end{array}\right]\right\}\left\{\left\{\begin{array}{l}
\left\{U_{n}\right\} \\
\left\{V_{n}\right\}
\end{array}\right\}=0\right.
\end{aligned}
$$

Unlike Eq. (16), which involves a summation on all modes $n$, Eqs. (17) and (18), do not involve a summation. Thus, for a given mode $n$, the corresponding eigenvalue problem involves only the nodal displacement vectors $\left\{U_{n}\right\}$ and $\left\{V_{n}\right\}$, but not $\left\{U_{m}\right\},\left\{V_{m}\right\} m \neq n$. The size of the resulting eigenvalue problems is particularly small, resulting in significant computational efficiency.

\section{Verification}

In this section, the buckling pressures are provided for sandwich pipe systems with internal pipe mean radius $R_{\text {int }}$, internal pipe thickness $d_{1}$, external pipe mean radius $R_{\text {ext }}$ external pipe thickness $d_{3}$, core thickness of $d_{2}$. The results are based on (a) the present formulation, (b) the solution of Sato and Patel (2007), (c) ABAQUS CPE8R element solution, (d) the simplified solution presented in Brush and Almroth (1975), and (e) the solution of Arjomandi and Taheri (2011). Table 3 shows the buckling pressures and corresponding buckling mode numbers for a sandwich system with an external mean radius of $300.0 \mathrm{~mm}$ and a thickness of $9.0 \mathrm{~mm}$, and an internal pipe with a $9.0 \mathrm{~mm}$ thickness. The radius of the internal pipe was varied so that the core thickness ranged from $50 \mathrm{~mm}$ to $85 \mathrm{~mm}$, to $115 \mathrm{~mm}$. Also, the material modular ratio $e=E_{s} / E_{c}$ was varied to take the values $10^{4}, 10^{3}$, and 20 , resulting in nine parametric run combinations. Buckling pressure predictions based on the current study are observed to agree with those based on other methods when the core stiffness is relatively low relative to that of the internal and external pipes (i.e. $e=10^{3}$ and $10^{4}$ ). When the core stiffness increases (i.e., $e=20$ ) the difference in buckling pressures becomes 
significant especially when the core is thick (i.e., $115 \mathrm{~mm}$ ). In this case, under the Sato and Patel solution, the governing buckling mode was $n=18$ while in both the current study and ABAQUS the governing buckling mode corresponded to $n=2$. A second set of runs was conducted for an external pipe mean radius of $300.0 \mathrm{~mm}$ and thickness of $15.0 \mathrm{~mm}$. The internal pipe thickness was kept at $9.0 \mathrm{~mm}$. As in the first set of parametric runs, both the modular ratio and the core thickness were varied. The corresponding results are provided in Table 3. Generally, there is good agreement between all five solutions when the core is soft. For thicker or stiffer cores, the present solution agrees well with Abaqus, but departs from other solutions. When the core stiffness is low relative to that of the internal and external pipes (i.e. $e=10^{4}$ ) and the core thickness is 115 and $85 \mathrm{~mm}$, all solutions predict Mode 4 as the governing buckling configuration. For a core thickness of $115 \mathrm{~mm}$, by increasing the core stiffness (i.e., $e=1000$ ), the governing buckling configuration corresponds to Mode 6. However, when the core stiffness increases, the differences become significant for a core thickness of $115 \mathrm{~mm}$ and $E_{S} / E_{c}=20$. In such a case, the current study predicts a buckling pressure twice as large as that predicted by Sato and Patel.

Table 3 Comparison of Critical Pressure $P_{c r}\left(M N / \mathrm{mm}^{2}\right)\left(R_{e x t}=300 \mathrm{~mm}, d_{1}=9.0 \mathrm{~mm}\right)$

\begin{tabular}{|c|c|c|c|c|c|c|c|c|c|c|c|}
\hline & $\frac{E_{s}}{E_{c}}$ & $\begin{array}{c}d_{2}{ }^{*} \\
(\mathrm{~mm})\end{array}$ & \begin{tabular}{|c}
$(1)$ \\
Current \\
Study \\
\end{tabular} & \begin{tabular}{|c|}
$(2)$ \\
Sato and \\
Patel
\end{tabular} & $\begin{array}{c}(3) \\
\text { Abaqus }\end{array}$ & $\begin{array}{c}(4) \\
\text { Brush and } \\
\text { Almroth } \\
\end{array}$ & $\begin{array}{c}\text { (5) } \\
\text { Arjomandi } \\
\text { and Taheri }\end{array}$ & $\frac{(2)}{(1)}$ & $\frac{(3)}{(1)}$ & $\frac{(4)}{(1)}$ & $\frac{(5)}{(1)}$ \\
\hline \multirow{9}{*}{$\begin{array}{l}d_{3}= \\
9.0 \\
(\mathrm{~mm})\end{array}$} & \multirow{3}{*}{$10^{4}$} & 115 & 10.0 & 10.6 & 10.1 & \multirow{3}{*}{$8.29^{(3)}$} & 11.4 & 1.06 & 1.01 & 0.83 & 1.14 \\
\hline & & 85 & 7.86 & 8.42 & 7.90 & & 8.29 & 1.07 & 1.00 & 1.06 & 1.05 \\
\hline & & 50 & 5.66 & 6.07 & 5.69 & & 5.94 & 1.07 & 1.00 & 1.46 & 1.05 \\
\hline & \multirow{3}{*}{$10^{3}$} & 115 & 36.4 & 40.5 & 38.5 & \multirow{3}{*}{$36.5^{(5)}$} & 37.3 & 1.11 & 1.06 & 1.00 & 1.03 \\
\hline & & 85 & 26.2 & 29.2 & 27.6 & & 27.5 & 1.11 & 1.05 & 1.39 & 1.05 \\
\hline & & 50 & 16.8 & 18.5 & 17.4 & & 17.7 & 1.10 & 1.04 & 2.17 & 1.05 \\
\hline & \multirow{3}{*}{20} & 115 & 910 & $570^{(18)}$ & 1115 & \multirow{3}{*}{$497^{(18)}$} & 1279 & 0.62 & 1.22 & 0.55 & 1.40 \\
\hline & & 85 & 613 & $570^{(18)}$ & 695 & & 952 & 0.93 & 1.13 & 0.81 & 1.55 \\
\hline & & 50 & 293 & 324 & 309 & & 581 & 1.10 & 1.05 & 1.7 & 1.98 \\
\hline \multirow{6}{*}{$\begin{array}{l}d_{3}= \\
15.0 \\
(\mathrm{~mm})\end{array}$} & \multirow{3}{*}{$10^{4}$} & 115 & 15.6 & 17.1 & 15.7 & \multirow{3}{*}{14.3} & 17.7 & 1.09 & 1.01 & 0.53 & 1.13 \\
\hline & & 85 & 13.5 & 14.8 & 13.5 & & 14.2 & 1.10 & 1.00 & 0.61 & 1.05 \\
\hline & & 50 & 11.2 & 12.4 & 11.3 & & 11.6 & 1.10 & 1.00 & 0.74 & 1.03 \\
\hline & \multirow{3}{*}{$10^{3}$} & 115 & 43.8 & 49.3 & 45.6 & \multirow{3}{*}{61.7} & 45.7 & 1.12 & 1.04 & 0.83 & 1.04 \\
\hline & & 85 & 33.4 & 37.5 & 34.5 & & 35.1 & 1.12 & 1.03 & 1.09 & 1.05 \\
\hline & & 50 & 23.6 & 26.5 & 24.3 & & 24.7 & 1.12 & 1.03 & 1.55 & 1.05 \\
\hline
\end{tabular}




\begin{tabular}{|c|c|c|c|c|c|c|c|c|c|c|}
\hline \multirow{3}{*}{20} & 115 & 1022 & $970^{(11)}$ & 1255 & \multirow{3}{*}{$827^{(11)}$} & 1386 & 0.95 & 1.23 & 0.49 & 1.36 \\
\hline & 85 & 714 & 863 & 812 & & 1041 & 1.21 & 1.14 & 0.70 & 1.46 \\
\hline & 50 & 370 & 422 & 392 & & 650 & 1.14 & 1.06 & 1.34 & 1.76 \\
\hline & & & Avera & & & & 1.02 & 1.06 & 1.23 & 1.26 \\
\hline & & & Idard De & iation & & & 0.16 & 0.07 & 0.51 & 0.33 \\
\hline
\end{tabular}

Note: In all cases, the governing buckling mode is $n=2$ except as indicated by a superscript (e.g., the first entry of Brush and Almroth of $8.29^{(3)}$ indicates that the buckling load is $8.29 \mathrm{kPa}$ and the corresponding buckling mode is $n=3$ )

Another set of comparisons was provided against the results of Sato and Patel (Figure 3 a-e) where the ratio of the buckling pressure for the sandwich system normalized with respect to the buckling pressure of the external pipe is plotted against the ratio $R_{\text {int }} / R_{\text {ext }}$ of the internal pipe mean radius to that of the external pipe. The solid lines denote results based on the present formulation while the discrete points were read from the graphs in Sato and Patel (2007). As a general observation, when the core stiffness is weak, the results are in good agreement. For thick cores, results are in good agreement except when $d_{3} / R_{\text {ext }}=d_{1} / R_{\text {ext }}=0.04$ and $v_{c}=0.4$ (Figure $3 \mathrm{a}$ ), which shows a larger discrepancy between both solutions. These discrepancies are attributed to the fact that the formulation in Sato and Patel neglected the effect of pre-buckling stresses undergoing non-linear strains. Where discrepancies between the present solution and that based on Sato and Patel results were observed, additional ABAQUS runs were conducted. In all cases, the present solution was found to be in closer agreement with ABAQUS results. Sato and Patel's results were reported to agree well with those of Brush and Almroth (1975) which do not account for the stiffness of the inside pipe. In contrast, in the present work (as is the case in the ABAQUS solution), the interaction between the whole sandwich system is thoroughly incorporated in the variational formulation. The difference between the underlying approaches is judged as a likely reason for the discrepancy observed. 


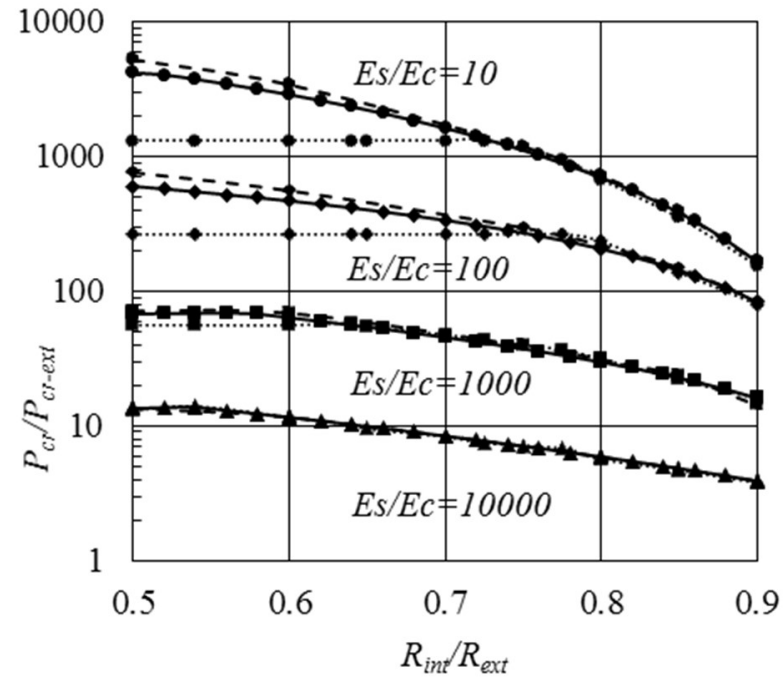

(a)

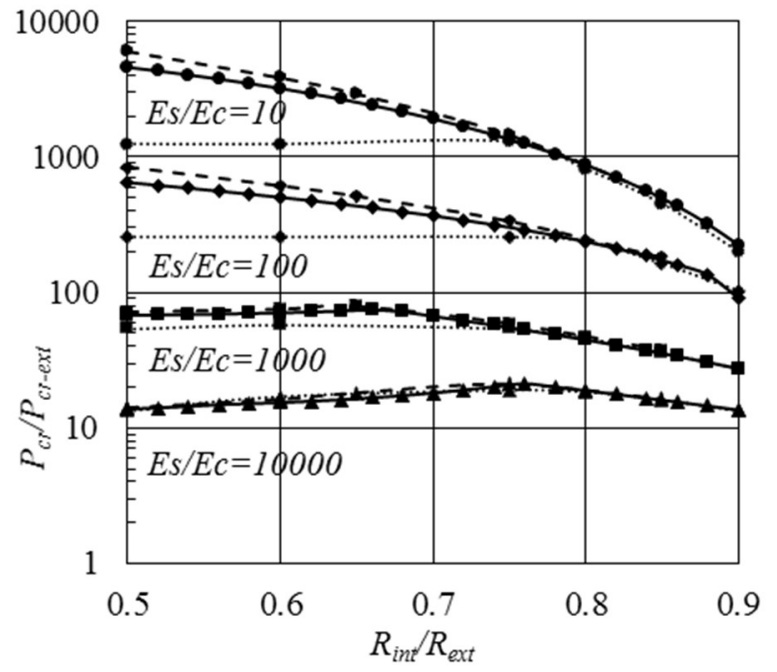

(c)

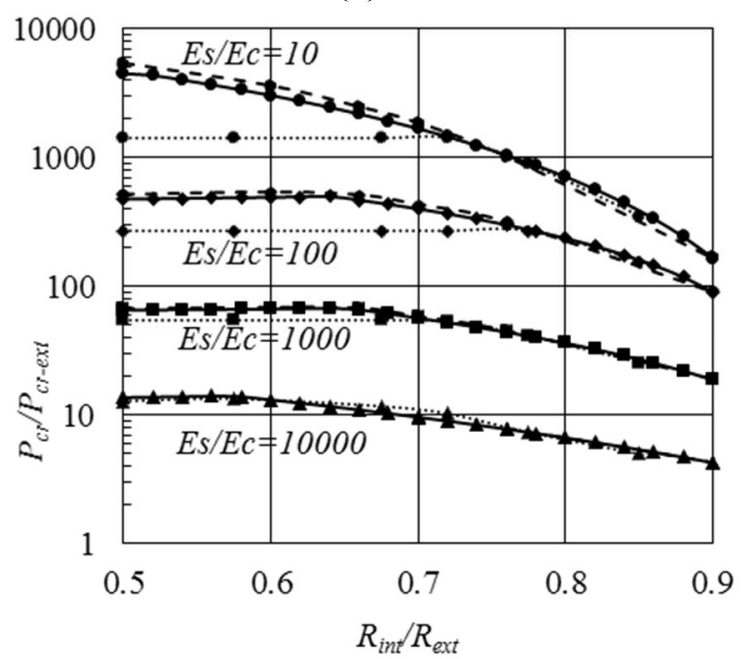

(e)

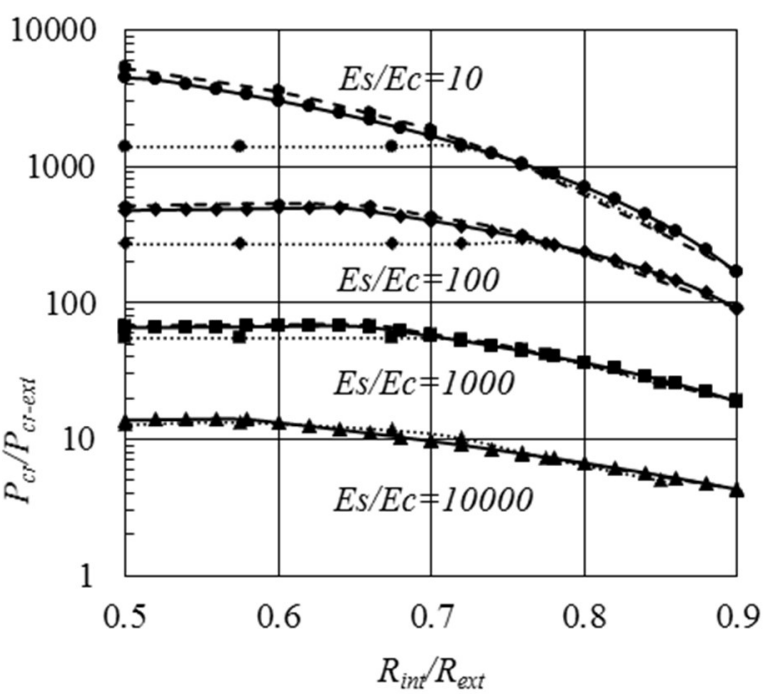

(b)

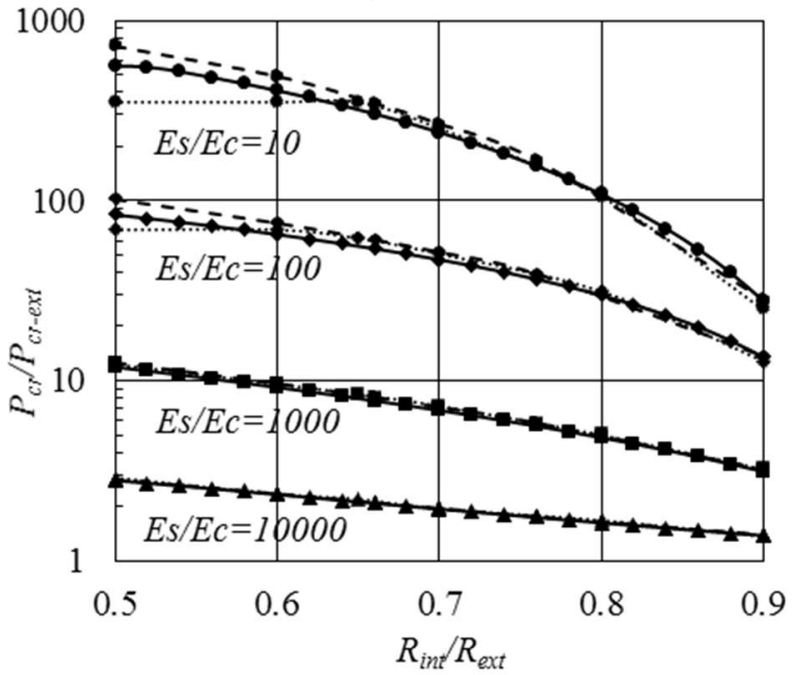

(d)

$\longrightarrow \mathrm{Es} / \mathrm{Ec}=10$ (Present Study)

$\longrightarrow-\mathrm{Es} / \mathrm{Ec}=100$ (Present Study)

$\rightarrow-E s / E c=1000$ (Present Study)

$\longrightarrow \mathrm{Es} / \mathrm{Ec}=10000$ (Present Study)

.......... Es/Ec $=10$ (Sato \& Patel)

…...... Es/Ec=100 (Sato \& Patel)

.......... Es/Ec=1000 (Sato \& Patel)

…....... Es $/ E c=10000$ (Sato \& Patel)

- - $\mathrm{Es} / \mathrm{Ec}=10$ (ABAQUS)

$-\rightarrow-\mathrm{Es} / \mathrm{Ec}=100$ (ABAQUS)

$--\mathrm{Es} / \mathrm{Ec}=1000$ (ABAQUS)

$--\$-\mathrm{Es} / \mathrm{Ec}=10000$ (ABAQUS) 
Figure 3 a-d Non-dimensional buckling pressure versus $R_{\text {int }} / R_{\text {ext }}$ for (a) $\left(R_{\text {ext }} / d_{3}\right)=\left(R_{\text {ext }} / d_{1}\right)=50$ and $v_{c}=0.4$, (b)

$$
\begin{gathered}
\left(R_{e x t} / d_{3}\right)=\left(R_{e x t} / d_{1}\right)=50 \text {, and } v_{c}=0.1,(\mathrm{c})\left(R_{\text {ext }} / d_{3}\right)=50,\left(R_{\text {ext }} / d_{1}\right)=25 \text { and } v_{c}=0.4,(\mathrm{~d})\left(R_{\text {ext }} / d_{3}\right)=25,\left(R_{\text {ext }} / d_{1}\right)=50 \\
\text { and } v_{c}=0.4 \text {, and (e) }\left(R_{\text {ext }} / d_{3}\right)=\left(R_{\text {ext }} / d_{1}\right)=25 \text { and } v_{c}=0.4
\end{gathered}
$$

\section{Parametric Runs}

\subsection{Motivation}

While the previous section has focused on assessing the validity of the model compared to other solutions, the present section adopts the model to generate a series of parametric runs. When designing an offshore pipe, the inside diameter (ID) of the inside pipe is known a-priori based on discharge requirements as determined from hydraulic considerations. A structural designer may then be required to assess structural design scenarios involving core thickness, core material properties, inside and outside pipe thickness, etc. on the critical external pressure of the system. Thus, in the following sections, a reference case is defined as a base case. Systematic deviations from the reference case are then considered while changing one parameter at a time. In each case, the critical external pressure of the system is quantified.

\subsection{Reference Case}

A reference sandwich pipe with zero internal pressure is considered (Figure 4). The sandwich system consists of a $1626 \mathrm{~mm}$ OD external steel pipe with a thickness $d_{3}=25.4 \mathrm{~mm}$ and $1,118 \mathrm{~mm}$ OD internal steel pipe with a thickness $d_{1}=23.8 \mathrm{~mm}$ thickness. The corresponding core layer thickness is $228.6 \mathrm{~mm}$. Pipe steel properties are $E_{s}=200,000 M P a, v_{s}=0.30$ and core properties are $E_{c}=200 \mathrm{MPa}, v_{c}=0.40$ (Figure 4). The system is subjected to an external pressure $P_{\text {ext }}$. The critical pressure $P_{c r}$ for the sandwich system is sought. 


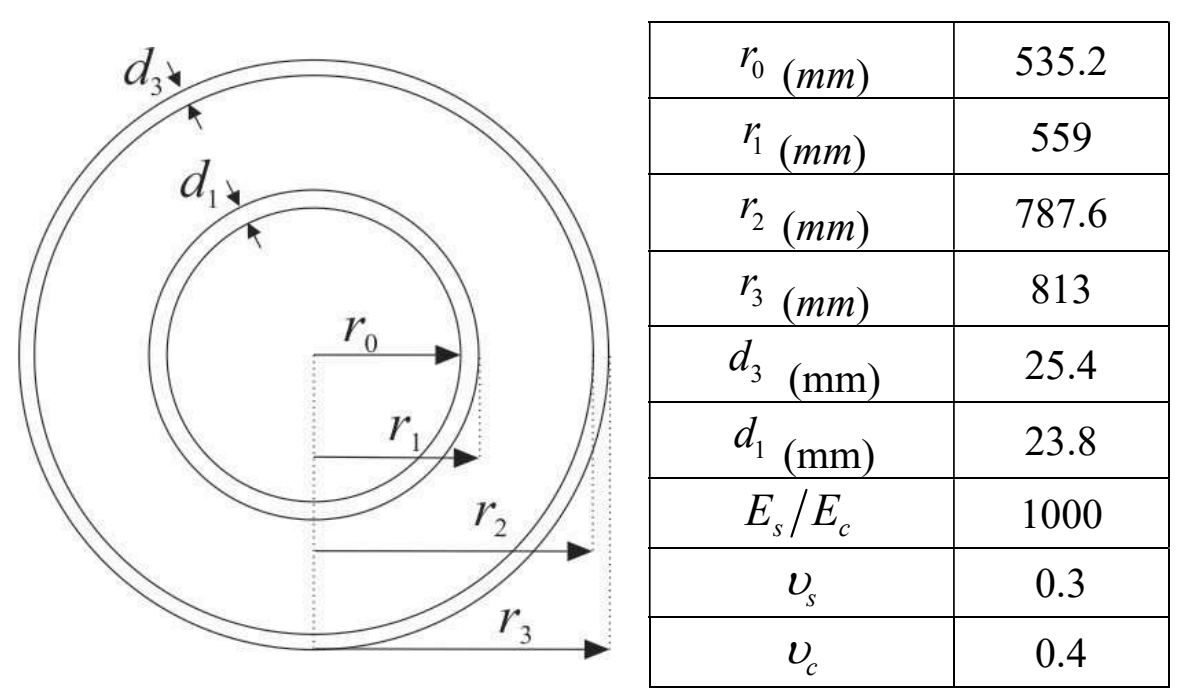

Figure 4 Geometric and material characteristic of the reference case

\subsection{Finite Element Mesh Study}

Figure 5 shows a mesh sensitivity analysis for the reference case. Convergence is attained with a minimal number of degrees of freedom. Using 10 elements per layer of the sandwich pipe system is observed to yield critical pressures within a $0.08 \%$ difference from those based on the finest mesh adopted (involving 15 elements in the cores and 13 elements for each of the steel pipes). Thus, 10 elements per layer are taken in subsequent runs.

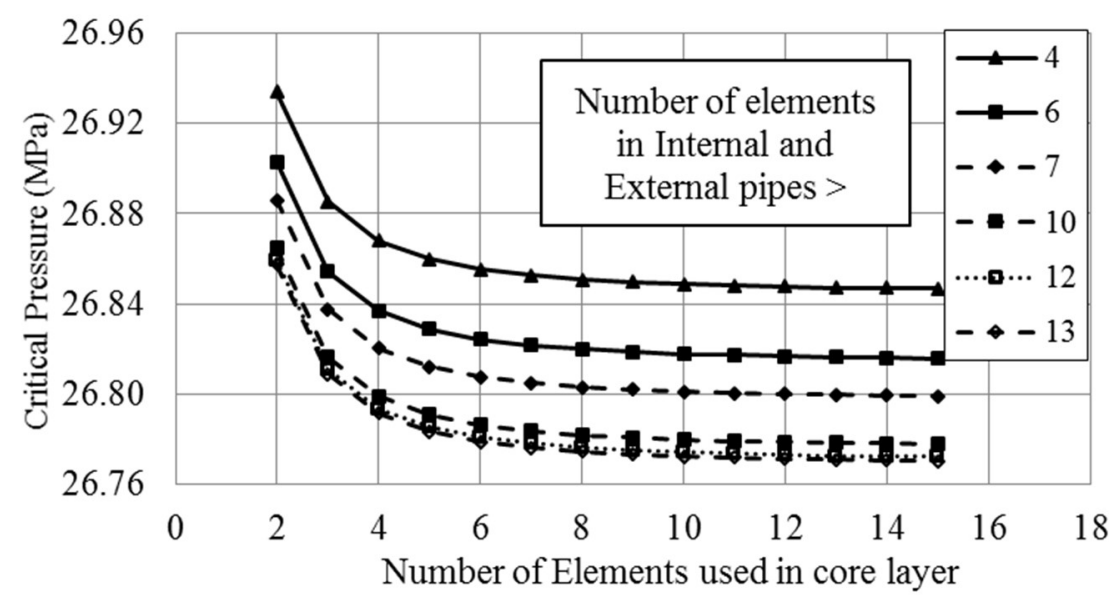

\subsection{Results}

Figure 5 Mesh study for FE solution of the present study on R01

\subsubsection{Effective stresses corresponding to buckling pressure}

For the reference case, the critical pressure is observed to correspond to Mode 2, which corresponds to the ovalization of the sandwich pipe system and take the value $26.8 \mathrm{MPa}$. Mode 2 
corresponds to ovalization while the higher modes correspond to more complex buckling configurations. Results based on a on the plain strain analysis in ABAQUS was provided for comparison (Figure 6). The analysis is based on the eight-noded-element CPE8R with 2 translational degrees of freedom per node, an 45 elements circumferentially and 10 elements radially to represent each of the three layers. The corresponding buckling pressure is $28.1 \mathrm{MPa}$, which corresponds to a $4.85 \%$ difference.

Given the eigen value $\lambda$ obtained from the buckling analysis, the stresses at the point of onset of buckling were calculated from the expressions $\sigma_{r}=\left(L_{i} / v_{i}\right)\left[\left(1-v_{i}\right) \varepsilon_{r}+v_{i} \varepsilon_{\theta}\right]$, $\sigma_{\theta}=\left(L_{i} / v_{i}\right)\left[v_{i} \varepsilon_{r}+\left(1-v_{i}\right) \varepsilon_{\theta}\right], \sigma_{z}=L_{i}\left(\varepsilon_{r}+\varepsilon_{\theta}\right)$ and the corresponding von-Mises stress was calculated from the expression $\sigma_{e}=\sqrt{(1 / 2)\left[\left(\sigma_{r}-\sigma_{\theta}\right)^{2}+\left(\sigma_{r}-\sigma_{z}\right)^{2}+\left(\sigma_{z}-\sigma_{\theta}\right)^{2}\right]}$ along the radial coordinate. The results are depicted in Figure 7. Overlaid on the figure are stresses as predicted form ABAQUS. As shown on Figure 7, both solutions provide nearly identical von Mises stresses. The peak von-Mises stresses in the outside pipe attains 637.6MPa, suggesting the necessity of using a higher strength pipe. In contrast, the von-Mises stresses in the inside pipe attain only 109.3 $\mathrm{MPa}$, suggesting that either a lower strength pipe and/or a thinner pipe wall would have been adequate. Given the low elastic modulus of the core, the effective stresses within the core are observed not to exceed 1.61 MPa.

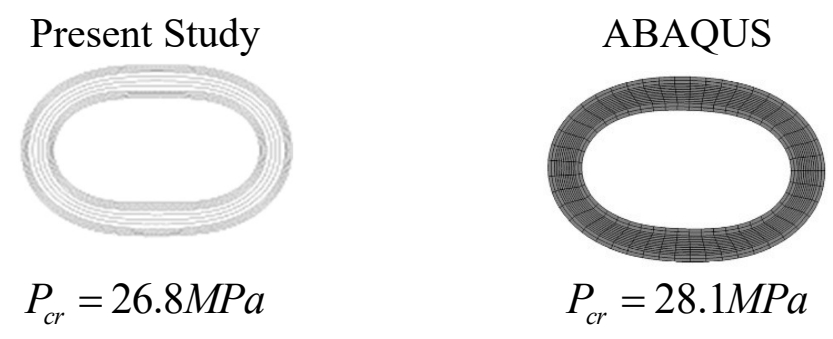

Figure 6 Comparison of buckling configuration between present study and ABAQUS 


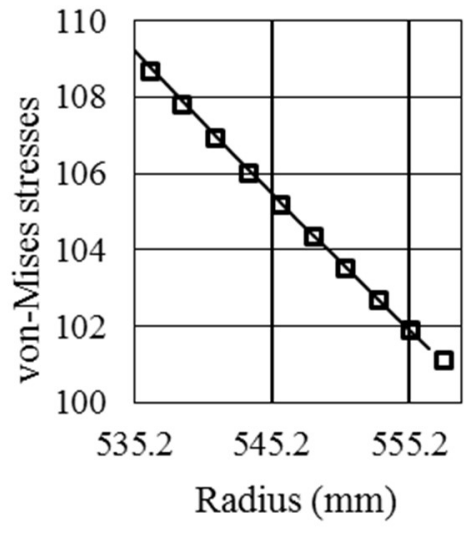

(a) Internal Pipe

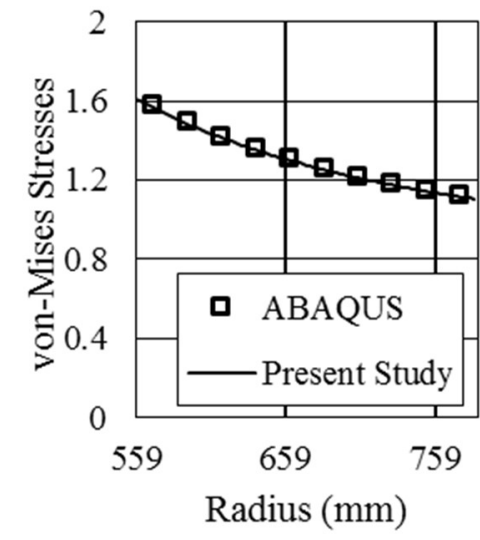

(b) Core Layer

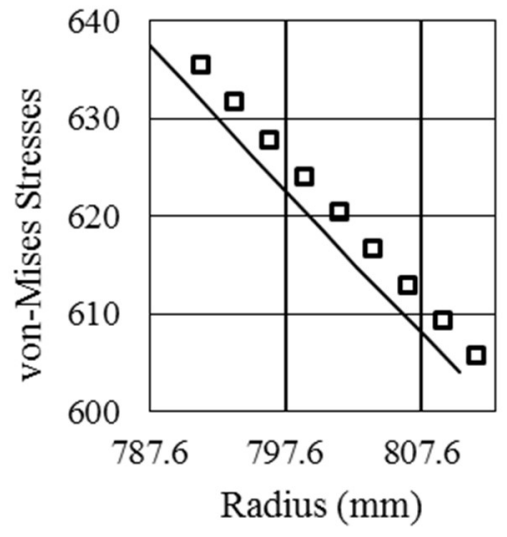

(c) External Pipe

Figure 7. von-Mises stresses of reference case R01 at onset of buckling for (a) Internal Pipe, (b) Core Layer, and (c) External Pipe

\subsubsection{Effect of internal pressure}

The effect of internal pressure on the external buckling pressure of the systems is depicted in Figure 8. The external buckling pressure is observed to increase with the internal pressure in a nearly linear manner. Thus, for the reference case considered in the present study, the critical pressure $P_{c r}$ can be estimated from the critical pressure $P_{c r 0}$ at no internal pressure through

$$
P_{c r} \approx P_{c r 0}+\alpha P_{i n t}
$$

where $\alpha=0.8863$. In Eq.(19), the correlation coefficient is $R_{1}^{2}=0.999$.

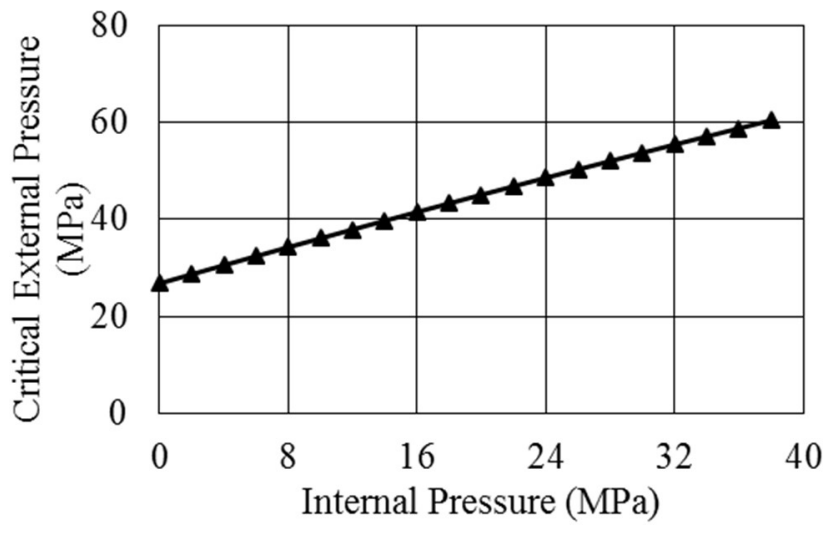

Figure 8 Effect of internal pressure on the buckling capacity of the reference case 


\subsubsection{Effect of the core material stiffness}

A series of parametric runs were conducted on sandwich pipe systems with geometric parameters identical to those of the reference case while considering various combinations of elastic moduli $E_{c}$ (ranging from $500 \mathrm{MPa}$ i.e., $e=E_{s} / E_{c}=400$ to $2000 \mathrm{MPa}$, i.e. $e=100$ ) and Poisson ratio $v_{c}$ (from 0.1 to 0.4 ) for the core layer (Figure 9). In all cases, Mode 2 was observed to correspond to the smallest buckling pressure. Stiffer cores are observed to significantly improve the buckling capacity of the system. In contrast, a decrease in the Poisson ratio is obseved to only mildly increase the critical pressure.

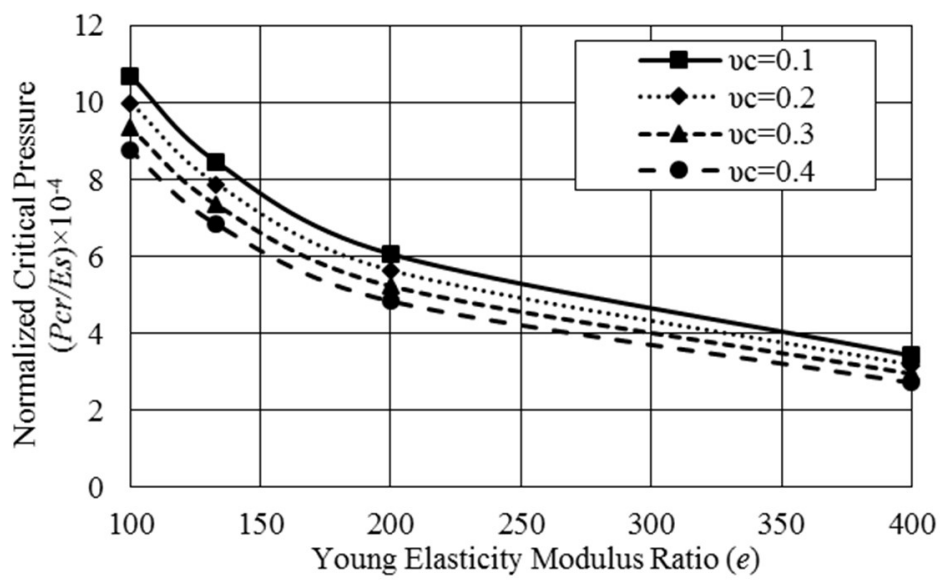

Figure 9 Normalized Critical Pressure (Pcr/Es) versus Elasticity Modulus Ratio (e) in (a) Scenario S1 and (b) Scenario S2 for Poisson ratios $\boldsymbol{v}_{\boldsymbol{c}}=0.1,0.2,0.3$, and 0.4

\subsubsection{Effect of steel pipe thicknesses}

In the present example, the sum of the thicknesses of the sandwich system $d_{1}+d_{2}+d_{3}$ is kept constant, while varying the internal pipe thickness $d_{1}$ (ranging from 6 to $30 \mathrm{~mm}$ ) and also the external pipe thickness $d_{2}$ (also ranging from 6 to $30 \mathrm{~mm}$ ) independently from $d_{1}$. For each case, a buckling analysis was conducted for various modes. Figure 10 shows that when the external pipe is relatively thin, the governing buckling pressure occurs at higher modes, which is about $20 \%$ less than the critical pressure at Mode 2. For instance, when the external pipe thickness increases to 10 $\mathrm{mm}$, and the internal pipe thickness is greater than $24 \mathrm{~mm}$, the governing buckling pressure takes place at Mode 12. Buckling in higher modes is observed to correspond to a significant reduction in the buckling capacity of the system, particularly when the thickness of the internal pipe is small. Figure 10 (b) shows that when the external pipe thickness ranges between $5-10 \mathrm{~mm}$ or $14-30 \mathrm{~mm}$, 
the critical pressure increases significantly. In contrast, the gain in buckling pressure capacity achieved within the $10 \mathrm{~mm}-14 \mathrm{~mm}$ range is observed to be minimal. In this range, it would thus be more beneficial to increase the thickness of the internal pipe as evidenced by the steeper slopes observed in Figure 10 (a).

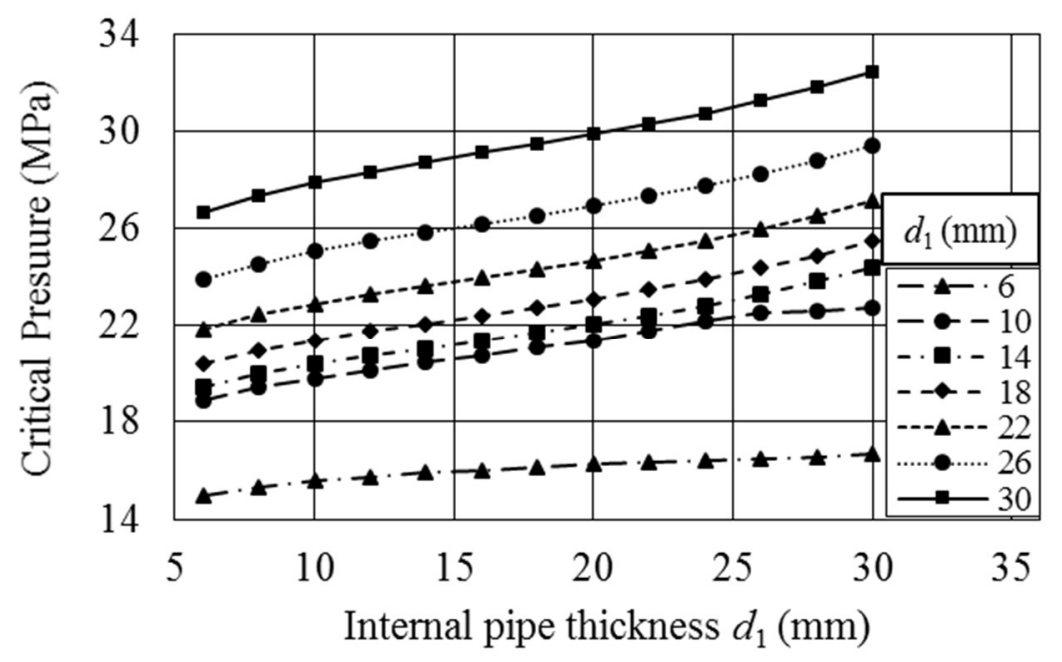

(a)

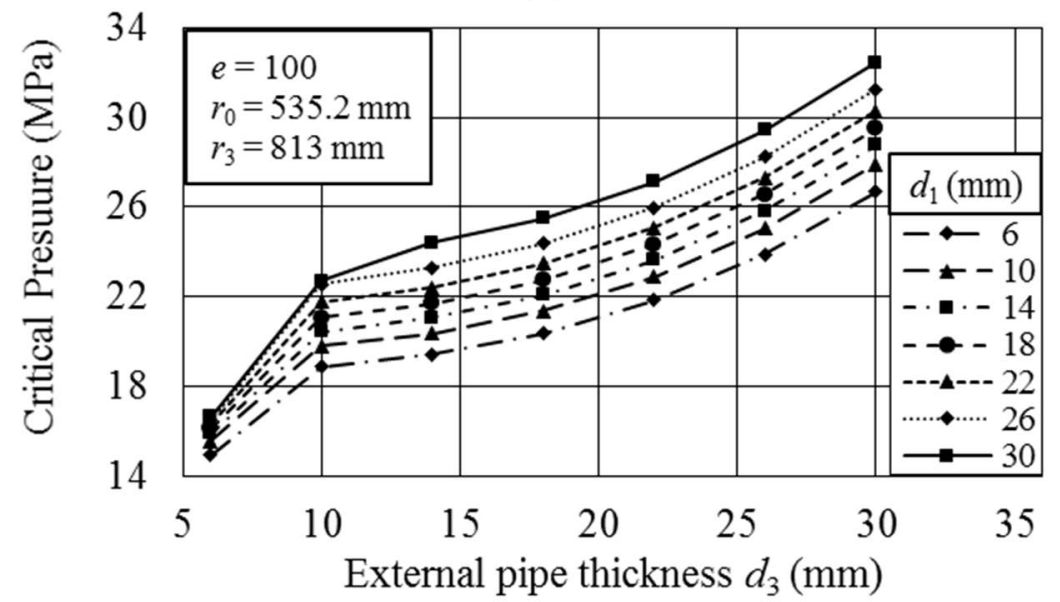

(b)

Figure 10 Effect of steel pipe thicknesses where internal radius $r_{0}$ is $535.2 \mathrm{~mm}$, external radius $r_{3}$ is $813 \mathrm{~mm}$, and elastic modulus ratio $e$ is 1000 , a) critical pressure versus internal pipe thickness, b) critical pressure versus external pipe thickness.

The effect of thickness to radius ratio for the internal and external pipes, $t_{\text {int }} / R_{\text {int }}$ and $t_{\text {ext }} / R_{\text {ext }}$ is investigated in another set of runs. Figure 11 provides the normalized buckling pressure $\left(P_{c r} / E_{s}\right)$ 
of a system with a elastic modulus ratio $e=E_{s} / E_{c}=1000$ and a pipe thickness ratio $d_{3} / d_{1}=1.10$ while the parameters $t_{\text {int }} / R_{\text {int }}$ and $t_{\text {ext }} / R_{\text {ext }}$ were varied as indicated in the figure.

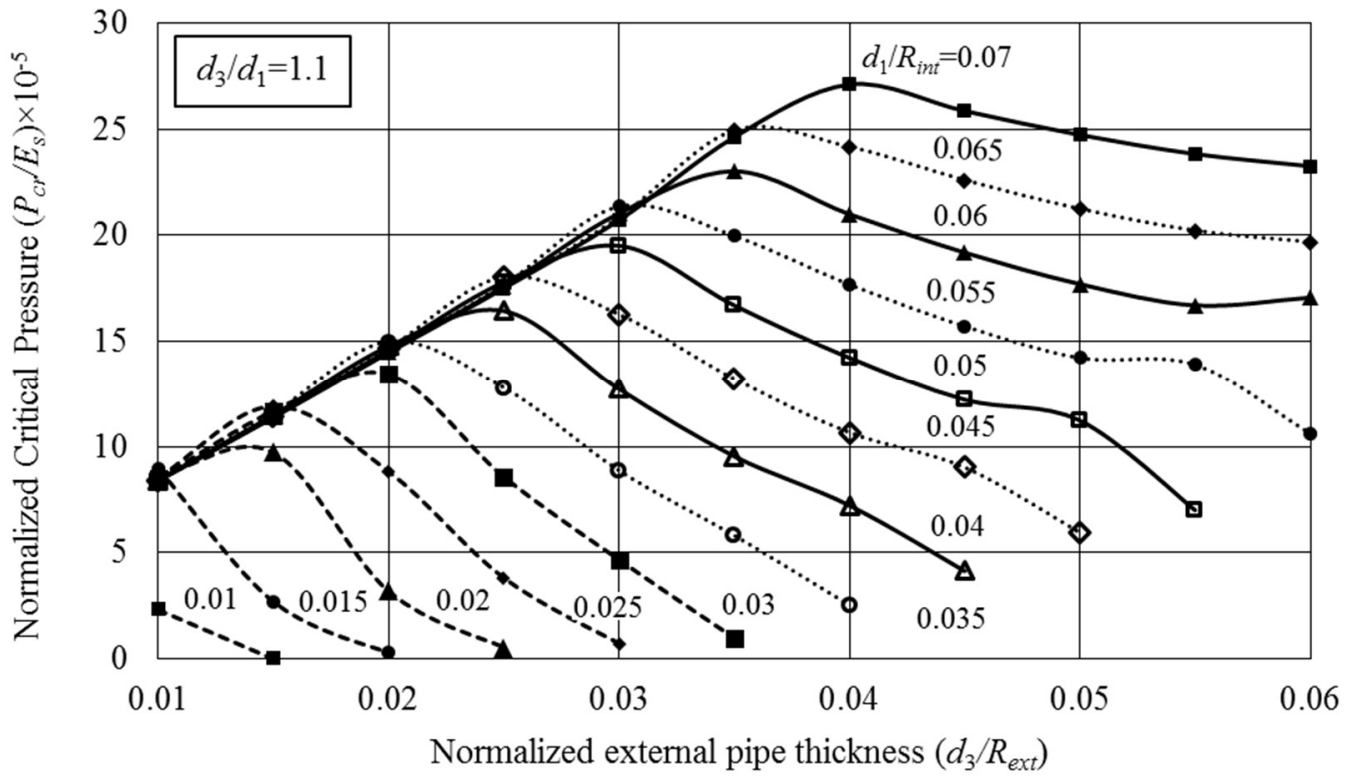

Figure 11 Normalized external pressure $P_{c r} / E_{s}$ versus normalized external pipe thickness $d_{3} / R_{\text {ext }}$ for various internal thicknesses $\left(d_{1} / R_{\text {int }}\right.$ ranging from 0.015 to 0.07 as marked on figure and $\left.d_{3} / d_{1}=1.1\right)$

\subsubsection{Effect of core thickness}

A set of parametric runs were conducted in which all parameters were taken identical to those of the reference case R01 (Section 6.2) with the exception of the core thickness. This was achieved by varying the outside radius $\left(R_{e x t}\right)$ of the external pipe. Figure 12 provides the critical nondimensional pressures corresponding to the first 15 modes. The buckling pressures were observed to correspond to Mode 2. Within the range of $R_{\text {ext }} / d_{3}$ considered, the buckling capacity is observed to increase with the radius to thickness ratio $R_{e x t} / d_{3}$ of the outside pipe. For the governing mode (Mode 2), the critical pressure magnitude shows a nearly linear trend with the $R_{\text {ext }} / d_{3}$. 


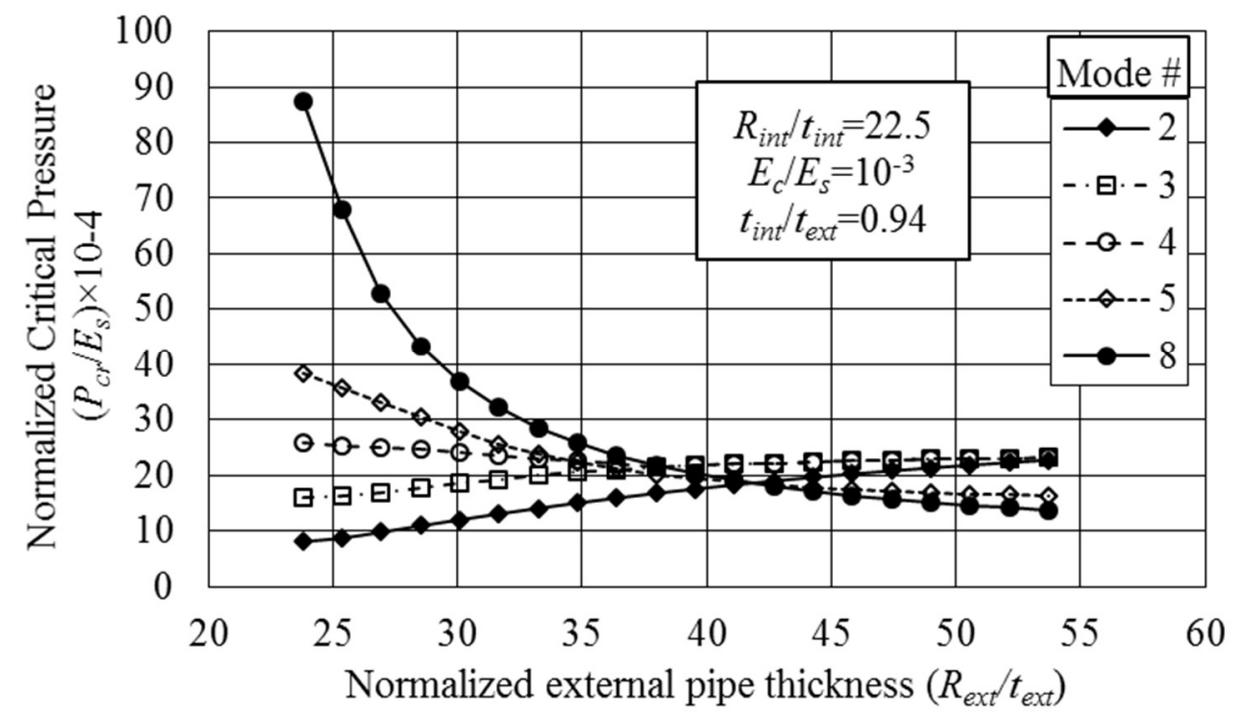

Figure 12 Effect of core thickness on critical pressure when the core thickness changes by varying the external pipe mean radius to its thickness ratio $\left(R_{\text {ext }} / d_{3}\right)$ while all other parameters (Elasticity Modulus ratio (e) is 1000 , the internal pipe mean radius to its thickness ratio $\left(R_{\text {int }} / d_{1}\right)$ is 22.5 , and internal pipe thickness to external pipe thickness ratio $\left(d_{1} / d_{3}\right)$ is 0.94$)$ are constant as indicated

\subsubsection{Summary of Findings}

in the figure

A summary of the results investigated is presented in (Table 4). As shown, the buckling capacity is highly dependent on the elastic Modulus and thickness of the core, and the external pipe radius to thickness ratio, and moderately on the internal pipe radius to thickness ratio and internal pressure and only mildly on the Poisson ratio of the core.

Table 4 Effect of different parameters on the buckling capacity of sandwich pipe

\begin{tabular}{|c|c|c|c|}
\hline \multirow{3}{*}{ Core } & $\begin{array}{c}\text { elastic modulus } \\
\text { ratio }\end{array}$ & $E_{c} / E_{s}$ & High \\
\hline & Poisson Ratio & $v_{c}$ & Low \\
\hline & Thickness & $R_{\text {int }} / R_{\text {ext }}$ & High \\
\hline \multirow{2}{*}{ Steel Pipes } & $\begin{array}{c}\text { Internal pipe radius } \\
\text { to thickness ratio }\end{array}$ & $R_{\text {int }} / t_{i n t}$ & Moderate \\
\hline & $\begin{array}{l}\text { External pipe radius } \\
\text { to thickness ratio }\end{array}$ & $R_{e x t} / t_{e x t}$ & High \\
\hline \multicolumn{2}{|c|}{ Internal Pressure } & $P_{i n t}$ & Moderate \\
\hline
\end{tabular}

\section{Summary and Conclusions}

The principle of stationary potential energy was used to obtain the pre-buckling equilibrium conditions and boundary conditions and the discretized finite element form of the neutral stability 
conditions for sandwich pipe systems. A Fourier series expansion of the displacement fields was adopted and was found to be particularly useful in transforming the 2D problem into a series of independent 1D problems, thus preserving the accuracy of the solution while keeping the degrees of freedom involved to a minimum. The finite element solution was used to analyze sandwich pipe systems consisting of two steel pipes with a soft core. A verification study was conducted through comparison with other solutions, and the validity of the formulation was established. The formulation features the following aspects:

1. It accounts for shear deformation effects and is thus suited for sandwich pipe systems with thick cores.

2. It involves two destabilizing terms: one is due to the external hydrostatic pressure and incorporates the follower effects, and the other one is due to the pre-bucking stresses undergoing the nonlinear components of the strains. The second contribution has been neglected in most published studies on sandwich pipes.

3. It adopts the Cauchy stress tensor and Green Lagrange strain tensor with constant constitutive relation as a work conjugate stress-strain-constitutive relation, which are energy-conjugate triplets, and thus is judged to provide a superior solution compared to most commercial software (Fu and Wass 2014), in which energy conjugacy is achieved only in an approximate sense.

Based on the parametric runs in the present study, the following conclusions can be drawn:

1. The hydrostatic internal pressure acting on the inside surface of the sandwich pipe increases the external buckling capacity of the system in a nearly linearly fashion.

2. The core elastic modulus has the most influence on the buckling capacity of the system. An increase in the Elasticity Modulus of the core material significantly increases the buckling capacity of the system. In contrast, an increase in Poisson's ratio for the core was observed to only mildly decrease the buckling capacity of the sandwich system.

3. In general, increasing the internal and external pipe thickness improves the buckling capacity of the system. In most cases, external pipe thickness is observed to be more influential in increasing the buckling pressure of the system. However, in a small range of 
thicknesses, increasing the internal pipe thickness is observed to be more effective in improving the capacity of the sandwich system.

4. The effect of core thickness on the buckling capacity depends on the thickness of internal and external pipes. When the internal and external pipes are thick, the buckling capacity of the system improves as the core thickness increases. However, when the internal and external pipes are thin, increasing the core thickness may result in decreasing the buckling capacity since higher buckling modes will govern the buckling capacity of the system.

\section{Acknowlegments}

The authors gratefully acknowlege financial support from the Natural Science and Engineering Research Council of Canada (NSERC) to the second author.

\section{Appendix 1}

This appendix provides coefficient matrices $\left[C_{e, u, n}\right],\left[C_{e, v, n}\right] \ldots$, and $\left[C_{g, u v, n, E}\right]$ introduced in the neutral stability conditions (Eq.16). Each of these matrices consists of smaller matrices with the following general format

$$
\left[C_{e, u, n}\right]=\left[\begin{array}{ccccc}
{\left[C_{e, u, n, 1}\right]} & \cdots & 0 & \cdots & 0 \\
\vdots & \ddots & & & \vdots \\
0 & & {\left[C_{e, u, n, j}\right]} & & 0 \\
\vdots & & & \ddots & \vdots \\
0 & \cdots & 0 & \cdots & {\left[C_{e, u, n, l}\right.}
\end{array}\right]
$$

where $j=1,2,3 \ldots, l$ represents the layer number and the matrices $\left[C_{e, u, n, j}\right],\left[C_{e, v, n, j}\right] \ldots$, and $\left[C_{g, u v, n, E, j}\right]$ are in the form of 


$$
\begin{aligned}
& {\left[C_{e, u, n, j}\right]=\left[\frac{\left(1-v_{j}\right)}{2 v_{j}}+\frac{\left(1-2 v_{j}\right)}{4 v_{j}} n^{2}\right]\left[\overline{\bar{A}}_{j}\right]+\frac{\left(1-v_{j}\right)}{2 v_{j}}\left[\overline{\bar{B}}_{j}\right]+\left[\overline{\bar{C}}_{j}\right]} \\
& {\left[C_{e, \mathrm{v}, n, j}\right]=\left[\frac{\left(1-v_{j}\right)}{2 v_{j}} n^{2}+\frac{\left(1-2 v_{j}\right)}{4 v_{j}}\right]\left[\overline{\bar{A}}_{j}\right]+\frac{\left(1-2 v_{j}\right)}{4 v_{j}}\left[\overline{\bar{B}}_{j}\right]-\frac{\left(1-2 v_{j}\right)}{2 v_{j}}\left[\overline{\bar{C}}_{j}\right]} \\
& {\left[C_{e, \mathrm{uv}, n, j}\right]=\left[\frac{\left(1-v_{j}\right)}{v_{j}} n+\frac{\left(1-2 v_{j}\right)}{2 v_{j}} n\right]\left[\overline{\bar{A}}_{j}\right]+n\left[\overline{\bar{C}}_{j}\right]^{T}-\frac{\left(1-2 v_{j}\right)}{2 v_{j}} n\left[\overline{\bar{C}}_{j}\right]} \\
& {\left[C_{\mathrm{g}, u, n, I, j}\right]=\frac{\left(1-v_{j}\right)}{2 v_{j}}\left(1+n^{2}\right)\left[\overline{\bar{A}}_{g 1, I, j}\right]+\frac{1}{2}\left(1+n^{2}\right)\left[\overline{\bar{A}}_{g 2, I, j}\right]+\frac{\left(1-v_{j}\right)}{2 v_{j}}\left[\overline{\bar{B}}_{g 1, I, j}\right]} \\
& +\frac{1}{2}\left[\overline{\bar{B}}_{g 2, I, j}\right]-\frac{1}{2} \frac{P_{i n t, j}}{L_{j}}[\bar{A}]_{r=r_{j-1}} \\
& {\left[C_{g, v, n, I, j}\right]=\frac{\left(1-v_{j}\right)}{2 v_{j}}\left(1+n^{2}\right)\left[\overline{\bar{A}}_{g 1, I, j}\right]+\frac{1}{2}\left(1+n^{2}\right)\left[\overline{\bar{A}}_{g 2, I, j}\right]+\frac{\left(1-v_{j}\right)}{2 v_{j}}\left[\overline{\bar{B}}_{g 1, I, j}\right]} \\
& +\frac{1}{2} L_{j}\left[\overline{\bar{B}}_{g 2, I, j}\right]-\frac{1}{2} \frac{P_{i n t, j}}{L_{j}}[\bar{A}]_{r=r_{j-1}} \\
& {\left[C_{g, u v, n, I, j}\right]=2 \frac{\left(1-v_{j}\right)}{v_{j}} n\left[\overline{\bar{A}}_{g 1, I, j}\right]+2 n\left[\overline{\bar{A}}_{g 2, I, j}\right]-\frac{P_{i n t, j}}{L_{j}} n[\bar{A}]_{r=r_{j-1}}} \\
& {\left[C_{\mathrm{g}, u, n, E, j}\right]=\frac{\left(1-v_{j}\right)}{2 v_{j}}\left(1+n^{2}\right)\left[\overline{\bar{A}}_{g 1, E, j}\right]+\frac{1}{2}\left(1+n^{2}\right)\left[\overline{\bar{A}}_{g 2, E, j}\right]+\frac{\left(1-v_{j}\right)}{2 v_{j}}\left[\overline{\bar{B}}_{g 1, I, j}\right]} \\
& +\frac{1}{2}\left[\overline{\bar{B}}_{g 2, E, j}\right]+\frac{1}{2} \frac{P_{e x t, j}}{L_{j}}[\bar{A}]_{r=r_{j}} \\
& {\left[C_{g, v, n, E, j}\right]=\frac{\left(1-v_{j}\right)}{2 v_{j}}\left(1+n^{2}\right)\left[\overline{\bar{A}}_{g 1, E, j}\right]+\frac{1}{2}\left(1+n^{2}\right)\left[\overline{\bar{A}}_{g 2, E, j}\right]+\frac{\left(1-v_{j}\right)}{2 v_{j}}\left[\overline{\bar{B}}_{g 1, I, j}\right]} \\
& +\frac{1}{2} L_{j}\left[\overline{\bar{B}}_{g 2, E, j}\right]+\frac{1}{2} \frac{P_{e x t, j}}{L_{j}}[\bar{A}]_{r=r_{j}} \\
& {\left[C_{\mathrm{g}, \mathrm{uv}, n, E, j}\right]=\left\{2 \frac{\left(1-v_{j}\right)}{v_{j}} n\left[\overline{\bar{A}}_{g 1, E, j}\right]+2 n\left[\overline{\bar{A}}_{g 2, E, j}\right]+\frac{P_{e x t, j}}{L_{j}} n[\bar{A}]_{r=r_{j}}\right\}}
\end{aligned}
$$

where 


$$
\begin{aligned}
& P_{i n t, j}=\left\{\begin{array}{ll}
0 & j=2,3 \ldots, l \\
P_{i n t} & j=1
\end{array}, \quad P_{e x t, j}= \begin{cases}0 & j=1,2 \ldots, l-1 \\
P_{i n t} & j=l\end{cases} \right. \\
& {\left[\overline{\bar{A}}_{j}\right]=\left\{\int_{r_{j-1}}^{r_{j}} \frac{1}{r}[\bar{A}] d r\right\}, \quad\left[\overline{\bar{B}}_{j}\right]=\left\{\int_{r_{j-1}}^{r_{j}} r[\bar{B}] d r\right\}, \quad\left[\overline{\bar{C}}_{j}\right]=\left\{\int_{r_{j-1}}^{r_{j}}[\bar{C}] d r\right\}} \\
& {\left[\overline{\bar{A}}_{g 1, I, j}\right]=\left\{\int_{r_{j-1}}^{r_{j}} u_{p, I} \frac{1}{r^{2}}[\bar{A}] d r\right\}, \quad\left[\overline{\bar{A}}_{g 2, I, j}\right]=\left\{\int_{r_{j-1}}^{r_{j}} \frac{u_{p, I}^{\prime}}{r}[\bar{A}] d r\right\}} \\
& {\left[\overline{\bar{B}}_{g 1, I, j}\right]=\left\{\int_{r_{j-1}}^{r_{j}} u_{p, I}^{\prime} r[\bar{B}] d r\right\}, \quad\left[\overline{\bar{B}}_{g 2, I, j}\right]=\left\{\int_{r_{j-1}}^{r_{j}} u_{p, I}[\bar{B}] d r\right\}} \\
& {\left[\overline{\bar{A}}_{g 1, E, j}\right]=\left\{\int_{r_{j-1}}^{r_{j}} u_{p, E} \frac{1}{r^{2}}[\bar{A}] d r\right\}, \quad\left[\overline{\bar{A}}_{g 2, E, j}\right]=\left\{\int_{r_{j-1}}^{r_{j}} \frac{u_{p, E}^{\prime}}{r}[\bar{A}] d r\right\}} \\
& {\left[\overline{\bar{B}}_{g 1, E, j}\right]=\left\{\int_{r_{j-1}}^{r_{j}} u_{p, E}^{\prime} r[\bar{B}] d r\right\}, \quad\left[\overline{\bar{B}}_{g 2, E, j}\right]=\left\{\int_{r_{j-1}}^{r_{j}} u_{p, E}[\bar{B}] d r\right\}}
\end{aligned}
$$

and

$$
\begin{aligned}
& {[\bar{A}]=\left\{N_{j}\right\}\left\langle N_{j}\right\rangle^{T}, \quad[\bar{B}]=\left\{N_{j}\right\}^{\prime}\left\langle N_{j}\right\rangle^{\prime T}} \\
& {[\bar{C}]=\left\{N_{j}\right\}\left\langle N_{j}\right\rangle^{\prime T}, \quad[\bar{D}]=\left\{N_{j}\right\}^{\prime}\left\langle N_{j}\right\rangle^{T}}
\end{aligned}
$$

\section{References}

Amazigo, J. C., and Fraser, W. B. (1971). "Buckling under external pressure of cylindrical shells with dimple shaped initial imperfections " International Journal of Solids Structures, 7, 18.

Amazigo, J. C., and Fraser, W. B. (1971). "Buckling under external pressure of cylindrical shells with dimple shaped initial imperfections " International Journal of Solids Structures, 7, 18.

Arjomandi, K., and Taheri, F. (2010). "Elastic buckling capacity of bonded and unbonded sandwich pipes under external hydrostatic pressure." Journal of Mechanics of Materials and Structures, 5(3), 391-409.

Bodner, S. R. (1958). "On the conservativeness of various distributed force systems." Journal ofThe Aeronautical Sciences 2. 
Brush, D. O., and Almroth, B. O. (1975). Buckling of bars, plates, and shells, McGraw-Hill, New York.

Fu, L., and Waas, A. M. (1995). "Initial post-buckling behavior of thick rings under uniform external hydrostatic pressure." Journal of Applied Mechanics, 62(2), 338-345.

Hashemian, R. (2014). "buckling analysis of sandwich pipes under external pressure." Masters of Applied Science in Civil Engineering, University of Ottawa, Ottawa, Canada.

Hashemian, R., and Mohareb, M. (2015). " Buckling analysis of sandwich pipes under external pressure " Rio Pipeline Conference \& Exposition 2015, Brazilian Petroleum, Gas and Biofuels Institute - IBP Rio de Janeiro, Brazil.

Hashemian, R., and Mohareb, M. (2016). "Finite difference model for the buckling analysis of sandwich pipes under external pressure." Ocean Engineering, 122, 172-185.

Hutchinson, J. W. (1968). "Buckling and Initial postbuckling behavior of oval cylindrical shells under axial compression." Journal of Applied Mechanics, 35(1), 66-72.

Ji, W., and Waas, A. M. (2013). "The two-dimensional elasticity solution for the buckling of a thick orthotropic ring under Eexternal pressure loading." Journal of Applied Mechanics, 81(1), 011005-011005.

Kardomateas, G. A. (1993). "Buckling of thick orthotropic cylindrical shells under external pressure." Journal of Applied Mechanics, 60(1), 195-202.

Kardomateas, G. A., and Simitses, G. J. (2004). "Buckling of long sandwich cylindrical shells under external pressure." Journal of Applied Mechanics, 72(4), 493-499.

Koiter, W. T. (1963). "Elastic stability and Postbuckling Behavior." Proceedings of the Symposium on Nonlinear Problems, 19.

Papadakis, G. (2008). "Buckling of thick cylindrical shells under external pressure: A new analytical expression for the critical load and comparison with elasticity solutions." International Journal of Solids and Structures, 45(20), 5308-5321.

Pearson, C. E. (1956). "General theory of elastic stability." Quarterly of Applied Mathematics, 14, 12. 
Sato, M., and Patel, M. H. (2007). "Exact and simplified estimations for elastic buckling pressures of structural pipe-in-pipe cross sections under external hydrostatic pressure." J Mar Sci Technol, $12(4), 251-262$.

Sato, M., Patel, M. H., and Trarieux, F. (2008). "Static displacement and elastic buckling characteristics of structural pipe-in-pipe cross-sections." Structural Engineering and Mechanics, $30(3), 263-278$.

Singer, J., and Babcock, C. D. (1970). "On the buckling of rings under constant directional and centrally directed pressure." Journal of Applied Mechanics, 37(1), 215-218.

Wah, T. (1967). "Buckling of thin circular rings under uniform pressure." International Journal of Solids and Structures, 3(6), 967-974.

\section{LIST OF SYMBOLS}

$\varepsilon_{\theta}, \varepsilon_{\theta}{ }^{*}, \varepsilon_{r}, \varepsilon_{r}{ }^{*}$ Strains and total strains in tangential $\theta$ and radial $r$ directions

$\varepsilon_{\theta, L, b}, \varepsilon_{\theta, N L, b} \quad$ Linear and non-linear strains in tangential direction due to the buckling pressure

$\varepsilon_{\theta, L, p}, \varepsilon_{\theta, N L, p} \quad$ Linear and non-linear strains in tangential direction due to the pre-buckling pressure

$\varepsilon_{\theta, p, I}, \varepsilon_{\theta, p, E} \quad$ Linear strains in tangential direction due to the pre-buckling internal and external pressure

$\varepsilon_{r, p, I}, \varepsilon_{r, p, E} \quad$ Linear strains in radial direction due to the pre-buckling internal and external pressure

$\varepsilon_{r, L, b}, \varepsilon_{r, N L, b} \quad$ Linear and non-linear strains in radial direction due to the buckling pressure

$\varepsilon_{r, L, p}, \varepsilon_{r, N L, p}$

$\varepsilon_{r \theta, L, b}, \varepsilon_{r \theta, N L, b}$

Pre-buckling Linear and non-linear strains in radial direction

$\varepsilon_{r \theta, L, p}, \varepsilon_{r \theta, N L, p}$

$\gamma_{r \theta}, \gamma_{r \theta}{ }^{*}$

Linear and non-linear shear strains due to the buckling pressure

$\theta, r$

Linear and non-linear shear strains due to the pre-buckling pressure

$\lambda$

$v_{j}$

$\Pi, \Pi_{p}$ Shear strain and total shear strain

Load multiplier as determined
Poisson's ratio for the layer $j$

$d_{j}, r_{j-1}, r_{j} \quad$ Thickness, internal radius, and external radius of the layer $j$

e Elastic modulus ratio $E_{s} / E_{c}$

1 Number of elements in the finite element solution 


$\begin{array}{ll}\mathrm{n} & \text { Fourier mode number } \\ u, v & \text { Radial and tangential displacement } \\ u^{*}, v^{*} & \text { Total radial and tangential displacement } \\ u_{b}, v_{b} & \text { Buckling radial and tangential displacement } \\ u_{p, j} & \text { Pre-buckling radial displacement of Layer } j \\ u_{p E}, u_{p I} & \text { Pre-buckling radial displacement due to external and internal pressure } \\ \text { ID, OD } & \text { respectively } \\ L_{j} & \text { Inside and outside diameters of the pipe cross section } \\ P_{c r} & \text { Came's constant for Layer } j \\ P_{e x t}, P_{i n t} & \text { External and internal pressure } \\ R_{i n t}, R_{e x t} & \text { mid-surface radius for internal and external pipes } \\ \mathrm{U} & \text { Internal strain energy } \\ \mathrm{V} & \text { Volume per unit length } \\ W_{1}, W_{2} & \text { Load potential energy gained by internal and external pressure }\end{array}$

